Article

\title{
Measuring Emissions from a Demonstrator Heavy-Duty Diesel Vehicle under Real-World Conditions-Moving Forward to Euro VII
}

\author{
Tommaso Selleri $^{1, *(\mathbb{D})}$, Roberto Gioria ${ }^{1}$, Anastasios D. Melas ${ }^{1} \mathbb{D}$, Barouch Giechaskiel ${ }^{1}$, Fabrizio Forloni ${ }^{1}$, \\ Pablo Mendoza Villafuerte ${ }^{2}$, Joachim Demuynck ${ }^{2}$ D , Dirk Bosteels ${ }^{2}$, Thomas Wilkes ${ }^{3}$, Oliver Simons ${ }^{3}$, \\ Patrick Recker ${ }^{3}$, Velizara Lilova ${ }^{4}$, Yusuke Onishi ${ }^{5}$, Matthias Steffen ${ }^{6}$, Benedikt Grob ${ }^{6}$, Adolfo Perujo ${ }^{1}$ \\ and Ricardo Suarez-Bertoa ${ }^{1, * \mathbb{D}}$
}

check for updates

Citation: Selleri, T.; Gioria, R.; Melas, A.D.; Giechaskiel, B.; Forloni, F.; Mendoza Villafuerte, P.; Demuynck, J.; Bosteels, D.; Wilkes, T.; Simons, O.; et al. Measuring Emissions from a Demonstrator Heavy-Duty Diesel Vehicle under Real-World Conditions-Moving Forward to Euro VII. Catalysts 2022, 12, 184. https://doi.org/10.3390/ catal12020184

Academic Editor: Jean-François Lamonier

Received: 11 January 2022 Accepted: 27 January 2022 Published: 1 February 2022 Publisher's Note: MDPI stays neutral with regard to jurisdictional claims in published maps and institutional affiliations.

Copyright: (C) 2022 by the authors. Licensee MDPI, Basel, Switzerland. This article is an open access article distributed under the terms and conditions of the Creative Commons Attribution (CC BY) license (https:// creativecommons.org/licenses/by/ $4.0 /)$.
1 European Commission, Joint Research Centre (JRC), 21027 Ispra, Italy; roberto.gioria@ec.europa.eu (R.G.); anastasios.melas@ec.europa.eu (A.D.M.); barouch.giechaskiel@ec.europa.eu (B.G.); fabrizio.forloni@ec.europa.eu (F.F.); adolfo.perujo@ec.europa.eu (A.P.)

2 AECC Aisbl, Association for Emissions Control by Catalyst, 1030 Schaerbeek, Brussels, Belgium; pablo.mendoza-villafuerte@aecc.eu (P.M.V.); joachim.demuynck@aecc.eu (J.D.); dirk.bosteels@aecc.eu (D.B.)

3 FEV Europe GmbH, 52078 Aachen, Germany; wilkes@fev.com (T.W.); simons@fev.com (O.S.); recker@fev.com (P.R.)

4 HORIBA Europe GmbH, Emission Engineering, Automotive Test Systems, 61440 Oberursel, Germany; velizara.lilova@horiba.com

5 HORIBA, Ltd., 1-15-1 Noka, Otsu-shi 520-0102, Shiga, Japan; yusuke.onishi@horiba.com

6 AIP GmbH \& Co. KG, 87490 Haldenwang/Allgäu, Germany; matthias.steffen@aip-automotive.de (M.S.); benedikt.grob@aip-automotive.de (B.G.)

* Correspondence: tommaso.selleri@ec.europa.eu (T.S.); ricardo.suarez-bertoa@ec.europa.eu (R.S.-B.)

\begin{abstract}
The European Union (EU) has introduced since the early 1990s a series of progressively more stringent emission regulations to control air pollution from the transport sector, commonly known as Euro standards. Following this path, more recently, with the European Green Deal, the European Commission has indicated the intention to review the current air pollutant emissions standards. This study investigates the emission performance of an advanced demonstrator vehicle developed to meet the increasingly more stringent air pollution limits required. Emissions of currently regulated and unregulated components including $\mathrm{NH}_{3}, \mathrm{~N}_{2} \mathrm{O}$, and $\mathrm{SPN}_{10}$ (solid particle number), were studied in a very wide range of real-world operative conditions. The performance of two new generation portable instruments for the onboard measurement of $\mathrm{N}_{2} \mathrm{O}$ and $\mathrm{NH}_{3}$ were also evaluated in comparison with reference laboratory equipment. Similarly, the measurement accuracy of onboard NOx sensors was also compared to laboratory reference. The vehicle presented low emissions of $\mathrm{NOx}$ and $\mathrm{NH}_{3}$ and relatively low emissions of $\mathrm{N}_{2} \mathrm{O}$, also compared to data currently available in the literature, in a broad range of operative conditions, which however resulted in a large variability in emissions.
\end{abstract}

Keywords: transport emissions; EU emissions regulation; unregulated pollutants; portable emission measurement systems

\section{Introduction}

The implementation of policies aimed at the reduction and control of air pollution has become a paramount challenge for the authorities worldwide, echoing a growing concern for environment and public health protection. Indeed, since the early 1990s, the EU has introduced a series of directives and regulations, commonly referred as Euro standards (Euro I to Euro VI step E for heavy-duty vehicles (HDVs)), aimed at curbing the contribution to air pollutants from the transport sector in Europe. This has resulted in a significant reduction in the emissions of a number of noxious compounds [1] and has contributed to 
the achievement of 2020 targets for the main air pollutants for EU as a whole [2]. However, despite this positive development, additional efforts are being discussed to counteract the effects of certain trends (such as increases in population and in economic output) currently eroding the beneficial effects of the aforementioned regulations [1].

Heavy-duty (HD) emission standards are historically based on engine performance. For this reason, the emission limits were defined in terms of mass per work performed over a duty cycle $(\mathrm{g} / \mathrm{kWh})$. The reason why the regulation focused on engines instead of vehicles is that the same HD engine could be used in very different applications (lorries, coaches, garbage collectors, etc.). Furthermore, even within the same application, very different vehicle architectures could use the same engine. Testing all possible configurations at type-approval would have resulted in burdensome, expensive, and potentially inefficient policies. To receive a European Commission (EC) type-approval, HD engines are subject to exhaust emission tests. The emissions of gaseous and particulate pollutants are determined using the World Harmonised Transient Cycle (WHTC) and/or the World Harmonised Steady-state Cycle (WHSC) test cycles. HD engines are also tested for off-cycle emissions (OCEs) and in-use emission tests (using portable emissions measurement systems, i.e., PEMS) at type-approval. The OCE and PEMS tests at type-approval ensure effective control of emissions under a broad range of engine and ambient operating conditions encountered during normal vehicle operation. Vehicles are successively tested under the in-service conformity (ISC) procedure, in order to ensure that the tailpipe emissions are effectively limited throughout their normal life under normal conditions of use. These tests are performed on-road using PEMS to overcome the need for removing the engine from the vehicle to assess the emissions.

Currently, the HD Euro VI Regulation (EC) No. 595/2009 [3] is in force and includes emission limits of $\mathrm{NOx}, \mathrm{CO}, \mathrm{PN}, \mathrm{PM}, \mathrm{NH}_{3}$ and $\mathrm{HC}$ for compression ignition engines. It introduced the in-use emission test using PEMS at type-approval and during ISC verifications on trips with specific characteristics (e.g., the share of urban, rural, and motorway operations). The ISC test is carried out on-road and, since the introduction of the Euro VI step E, includes the measurement of cold start emissions and all the pollutants regulated in the laboratory, the only exception being $\mathrm{NH}_{3}$.

Such regulation has driven the development of technologies for the drastic reduction of pollution derived from internal combustion engine (ICE) emissions, leading to the production and commercialisation of vehicles able to face the conflicting exigencies of increasing mobility by the public and goods on one hand, and the increasingly more stringent air pollution limits required by the environmental policies on the other. Indeed, to meet the requirements laid down by the procedures present in these emission standards, vehicle manufacturers have equipped their products with different emission control systems. In particular, to reduce NOx emissions, vehicles with a compression ignition engine have been equipped with systems such as selective catalytic reduction systems (SCRs), and/or exhaust gas recirculation systems (EGRs). However, while reducing the emissions of the target compounds, these systems can lead to the emissions of other pollutants that are not regulated from vehicles in the $\mathrm{EU}$, e.g., $\mathrm{NH}_{3}$ on-road [4], $\mathrm{N}_{2} \mathrm{O}$, and $\mathrm{SPN}_{10}$ [5]. In addition, among unregulated pollutants, also $\mathrm{HCHO}$ represents a concern. An extensive literature review on the topic has been recently published and is available to the interested reader [2].

Summarising, the future Euro VII regulation on heavy-duty vehicles appears to move in the direction of including additional pollutants within its scope, simplifying test conditions, and widening the set of regulated conditions [6]. In this respect, the objective of this study is to evaluate the emission performances of an advanced demonstrator vehicle in a broad range of operative conditions and for both currently regulated and unregulated components. This study also evaluates portable systems that allow the measurement of real-world emissions of $\mathrm{NH}_{3}$ and $\mathrm{N}_{2} \mathrm{O}$ from $\mathrm{HD}$ vehicles. 


\section{Materials and Methods}

\subsection{Vehicle and Tests}

The vehicle under test was a demonstrator vehicle based on a N3 Daimler Actros 1845 LS $4 \times 2$ tractor, equipped with a 12.8 litre Diesel engine with high pressure EGR and originally homologated to Euro VI step C. The rated power of the engine was $335 \mathrm{~kW}$ at $1600 \mathrm{rpm}$, with a maximum torque of $2200 \mathrm{Nm}$ at $1100 \mathrm{rpm}$ and a reference work on the WHTC cycle at type approval of $29.4 \mathrm{kWh}$, calculated according to regulation 595/2009 [3]. Additional information can be found in Table 1.

Table 1. Vehicle specifications.

\begin{tabular}{cc}
\hline Manufacturer and model & Mercedes-Benz Actros 1845 LS $4 \times 2$ \\
\hline Vehicle category & $\mathrm{N} 3$ \\
\hline Engine type & OM 471 2nd generation \\
\hline Engine configuration & 6 cylinders in line \\
\hline Engine size & $12,800 \mathrm{~cm}^{3}$ \\
\hline Maximum power & $335 \mathrm{~kW} @ 1600 \mathrm{rpm}$ \\
\hline Maximum torque & $2200 \mathrm{Nm} @ 1100 \mathrm{rpm}$ \\
\hline Fuel type & Diesel \\
\hline Emission control system configuration & ccDOC + ccSCR/ASC + DOC + catalysed DPF + \\
& SCR/ASC (thermally aged at 500k km equivalent) \\
\hline
\end{tabular}

The vehicle had a specifically designed emission control system composed of a closed coupled (cc) Diesel oxidation catalyst (DOC), SCR, and ammonia slip catalyst (ASC). The ccDOC was located downstream the turbocharger turbine to allow much faster heat up of the system, but in particular of the ccSCR. The positioning of a urea injector downstream the ccDOC takes advantage of the length of the down pipe and a dedicated mixer installed just after the injector, to achieve a good distribution of the urea into the ccSCR within the box. It was not possible to install the SCR closer to the engine within the engine compartment; however, it was decided to refer to it as close-coupled, as it was located significantly closer to the engine compared to the SCR position in the original system. The cCSCR/ASC was placed as the first component in the boxed system followed by a DOC, catalysed Diesel particulate filter (DPF) and SCR/ASC, with twin Diesel exhaust fluid (DEF) injection and an HC doser to support DPF regeneration. The emission control system was thermally aged to $500 \mathrm{k} \mathrm{km}$ equivalent. The components were hydrothermally aged in an oven at a temperature of $650{ }^{\circ} \mathrm{C}$ with runs performed with $10 \% \mathrm{H}_{2} \mathrm{O}$ in air. Its simplified schematic, including the position of Diesel Exhaust Fluid (DEF) and HC injection points as well as the sensors for $\mathrm{NOx}, \mathrm{NH}_{3}, \mathrm{~T}$, and pressure, is illustrated in Figure $\mathrm{S} 1$ in Supplementary Materials. A more detailed description of the design and the technical evolutions introduced in the demonstrator vehicle can be found in [7].

The vehicle was tested on a large variety of cycles in the laboratory. These included the World-Harmonised Vehicle Cycle (WHVC), which is a transposition on the chassis dynamometer of the Type Approval (TA) cycle (i.e., WHTC) that is normally performed only on the engine unit on a test bench. In addition, a Real-World Test (RWT), simulating a mix of urban, rural, and motorway driving representative of the normal conditions of use for this class of vehicles was performed. Furthermore, two different types of urban driving cycles that, although less typical for this truck, are more challenging due to prolonged low load and speed conditions were conducted. Finally idling, active regeneration, and aggressive combination of uphill motorway driving and low load operations (so-called Brenner cycle) were also explored. The tests were performed at different ambient temperature conditions ranging from $-7^{\circ} \mathrm{C}$ to $35^{\circ} \mathrm{C}$, using two different simulated payloads $(10 \%$ and $55 \%)$ and for the engine in cold and hot start conditions. Herein, cold indicates that the coolant and emission control system temperatures are both within $\pm 3{ }^{\circ} \mathrm{C}$ of ambient temperature. For 
some tests, a dedicated conditioning procedure was performed before the experiment; the vehicle was driven for approximately $30 \mathrm{~min}$, until the differential pressure change across the DPF was stable, at high speed $(70 \mathrm{~km} / \mathrm{h})$ with DEF dosing disabled. This promoted a certain degree of passive regeneration of the DPF, avoided the formation of deposits which might have ended up clogging the exhaust lines, and consumed the $\mathrm{NH}_{3}$ stored on the two SCR units. Hence, we had a priori a more challenging situation for the NOx emissions in the test performed after this conditioning. However, this might not be the case for $\mathrm{NH}_{3}$ and $\mathrm{N}_{2} \mathrm{O}$, as discussed in detail in the "Results and Discussion" Section 3. We clearly indicated when such a procedure was carried out, since this was not considered as a normal driving situation, unlike all the other tests performed on the vehicle. A summary of the conditions explored in this experimental campaign can be found in Table 2.

Table 2. Summary of tests performed (Euro VII demonstrator).

\begin{tabular}{ccccc}
\hline Type & $\begin{array}{c}\text { Starting } \\
\text { Condition }\end{array}$ & Payload (\%) & Ambient T ( $\left.{ }^{\circ} \mathbf{C}\right)$ & $\begin{array}{c}\text { Conditioning } \\
\text { Performed }\end{array}$ \\
\hline WHVC & Cold, Hot & 55 & $-7,0,23$ & yes, no \\
\hline Real World Test & Cold & 10 & $-7,23,35$ & yes \\
\hline Urban delivery & Cold & 10,55 & $-7,23$ & yes, no \\
\hline JRC city & Cold & 10 & -7 & yes \\
\hline Brenner cycle & Cold & 10 & -7 & no \\
\hline Idling & Hot & - & 23 & no \\
\hline $\begin{array}{c}\text { DPF } \\
\text { regeneration }\end{array}$ & Hot & - & 23 & no \\
\hline
\end{tabular}

A complete list of all the test cycles performed is reported in Table S1, together with the details of the speed profiles and road gradients in Figure S2, both in Supplementary Materials. Details on the determination of road load values can also be found in the "Vehicle and Tests" Section of the Supplementary Materials.

For comparison, additional data on gaseous emissions coming from a Euro VI step $\mathrm{C}$ vehicle and not previously published were also reported and analysed with the same procedure, presented in the following. In particular, the vehicle was a medium duty truck (between 12 and $15 \mathrm{t}$ max weight) with a 6-cylinder engine. This vehicle was tested on-road on Euro VI step C ISC trips (4 tests) and on a shorter on-road test during the actual day-today operation of the vehicle owner (4 tests). Examples of the speed and altitude profiles are reported in Figure S2. A summary of the tests performed on this second vehicle can be found in Table 3.

Table 3. Summary of tests performed (Euro VI step C).

\begin{tabular}{ccccc}
\hline Type & $\begin{array}{c}\text { Starting } \\
\text { Condition }\end{array}$ & Payload (\%) & Ambient T ( $\left.{ }^{\circ} \mathbf{C}\right)$ & $\begin{array}{c}\text { Conditioning } \\
\text { Performed }\end{array}$ \\
\hline ISC & Cold, Hot & 10,100 & 15 & $\mathrm{n} / \mathrm{a}$ \\
\hline $\begin{array}{c}\text { Day-to-day } \\
\text { operation }\end{array}$ & Cold & $\mathrm{n} / \mathrm{a}$ & 15,20 & $\mathrm{n} / \mathrm{a}$ \\
\hline
\end{tabular}

\subsection{VELA7 Heavy-Duty Test Cell}

VELA7 is the heavy-duty vehicles laboratory and, at present, one of the 10 facilities dedicated to vehicle and engine testing of the JRC of the European Commission in Ispra, Italy. All the results discussed in this work, with the exception of the literature data of the Euro VI step C demonstrator already mentioned, were obtained within this laboratory.

VELA7 is a climatic test cell which can operate between $-30{ }^{\circ} \mathrm{C}$ and $50{ }^{\circ} \mathrm{C}$, with controlled humidity and equipped with a 4 wheel-drive (4WD), 2-axis roller dynamometer 
specifically designed for heavy-duty vehicles. The vehicle was tested using only the front roller in 2WD mode. While it is possible to execute cold start tests at $-30{ }^{\circ} \mathrm{C}$ in VELA7, maintaining such a low temperature with a large heavy-duty vehicle would have been impractical, also for the proper functioning of the tunnel dilution system and the analysers sampling from it. For these reasons, the tests were performed at a minimum temperature of $-7^{\circ} \mathrm{C}$. The exhaust tailpipe was connected with a $9 \mathrm{~m}$ transfer line feeding a full dilution tunnel with a CVS (constant volume sampler) operating at a total flow rate of $100 \mathrm{~m}^{3} \cdot \mathrm{min}^{-1}$ as well as with a heated transfer line for raw measurement. Criteria pollutants such as $\mathrm{NOx}, \mathrm{CO}, \mathrm{HC}$, and $\mathrm{CH}_{4}$ were measured, together with $\mathrm{CO}_{2}$ and $\mathrm{O}_{2}$, using an AVL AMA i60 analyser measuring both diluted and raw exhaust. In the following, only raw emissions are discussed, and diluted measurement were used as internal reference. Additional information on sampling point configuration can be found in Figure S3 in Supplementary Materials.

VELA7 was also fitted out with a Fourier-Transform Infrared (FTIR) spectrometer (Nicolet Antaris IGS Analyser-Thermo Electron Scientific Instruments LLC, Madison, WI, USA) - AVL SESAM - that allows the measurement of a series of species typically found in the standard compounds library for Diesel engines (among others $\mathrm{NH}_{3}, \mathrm{~N}_{2} \mathrm{O}, \mathrm{HCHO}, \mathrm{NOx}$, $\mathrm{CO}, \mathrm{CO}_{2}, \mathrm{CH}_{4}$ ). The analyser included a Michelson interferometer (spectral resolution: $0.5 \mathrm{~cm}^{-1}$, spectral range: $600-3500 \mathrm{~cm}^{-1}$ ), a liquid nitrogen cooled mercury cadmium telluride detector, a multi-path gas cell with $2 \mathrm{~m}$ of optical path with a working pressure of $860 \mathrm{hPa}$, and a downstream sampling pump $\left(6.5 \mathrm{~L} \cdot \mathrm{min}^{-1}\right.$ flow rate). The overall acquisition frequency was $1 \mathrm{~Hz}$. The instrument was connected to the sampling point with a heated polytetrafluoroethylene (PTFE) sampling line $\left(191^{\circ} \mathrm{C}\right)$; see Figure S3 for additional details. A detailed description of the VELA7 facility and the sampling configuration can be found in [8].

Solid particle number (SPN) was measured from the dilution tunnel. A 489 (AVL List $\mathrm{GmbH}$, Graz, Austria) AVL particle counter (APC) compliant with the heavy-duty vehicle regulation [3] was employed for solid particle number measurements down to $23 \mathrm{~nm}$, $\mathrm{SPN}_{23}$. APC consisted of a hot dilution stage at $150{ }^{\circ} \mathrm{C}$, an evaporation tube operating at $350{ }^{\circ} \mathrm{C}$, a cold dilution stage, and a condensation particle counter (CPC) with a $50 \%$ cut-off size at $23 \mathrm{~nm}$. Additionally, solid particle number down to $10 \mathrm{~nm}, \mathrm{SPN}_{10}$, was measured with a TSI (Shoreview, MN, USA) 3792 CPC with $65 \%$ counting efficiency at $10 \mathrm{~nm}$, which sampled from the cold dilution stage of the APC. Please note that for two RWT $\left(23^{\circ} \mathrm{C}\right.$ and $-7^{\circ} \mathrm{C}$ ), due to a data logging issue, $\mathrm{SPN}_{10}$ measurements were not available.

In addition, specifically for this campaign, a laboratory grade Quantum Cascade Laser Infrared (QCL-IR) spectrometer (HORIBA MEXA 1400QL-NX, Horiba Ltd., Kyoto, Japan) was used to measure $\mathrm{NO}, \mathrm{NO}_{2}, \mathrm{~N}_{2} \mathrm{O}$, and $\mathrm{NH}_{3}$. This was done to collect additional data to better assess the performances of two new mobile instruments currently under development and of potential interest for Euro 7/VII regulation. These instruments are described in the next section. The QCL system consisted of three major components: a main control unit, an analyser unit, and a heated filter containing a quartz element specifically designed to minimise the adsorption of the ammonia molecules present in the exhaust gas. The filter was connected to the analyser unit via a vacuum sample transfer line maintained at a temperature of $113{ }^{\circ} \mathrm{C}$. The sampling of the exhaust was conducted via a stainless-steel sampling probe covered with a heated jacket in order to avoid cold spots. The analyser had an acquisition frequency of $10 \mathrm{~Hz}$.

\subsection{Portable Instruments for $\mathrm{NH}_{3}$ and $\mathrm{N}_{2} \mathrm{O}$ Measurement}

Two portable instruments, designed for on-board measurement of $\mathrm{NH}_{3}$ and $\mathrm{N}_{2} \mathrm{O}$, were used in parallel with the standard laboratory setup already described. Both instruments sampled raw exhaust, according to the scheme in Figure S3.

The first instrument was an OBS-ONE-XL from HORIBA, based on the Infrared Laser Absorption Modulation (IRLAM) technique and using a QCL as a light source. In the IRLAM technique, feature quantities are extracted from an absorption spectrum, which 
is obtained by modulating the wavelength of QCL light around an absorption peak of a target gas. Then a corrected concentration of the target gas is determined with the feature quantities instead of the absorption spectrum. This approach not only significantly reduces the computation load but also improves the measurement accuracy by correcting various disturbances such as a laser wavelength drift, spectral interferences, and broadening by means of extracting the corresponding feature quantities. Additional details can be found in [9].

The OBS-ONE-XL consisted of three main elements: a sampling probe, the analyser, and a laptop. The sampling probe used in this setup has a length of $6 \mathrm{~m}$ and a PTFE inner tube with an in-line filter and is heated at $113^{\circ} \mathrm{C}$ in order to ensure fast response time, low adsorption, and no condensation. The in-line quartz filter element was specifically designed for the measurement of $\mathrm{NH}_{3}$ emissions. The heated and filtered sample was flowed through a specifically designed Herriott cell, with an optical path length of $5 \mathrm{~m}$ which was operated at $113{ }^{\circ} \mathrm{C}$ and $50 \mathrm{kPa}$. The wavelengths of the QCLs for measuring $\mathrm{N}_{2} \mathrm{O}$ and $\mathrm{NH}_{3}$ were around $7.8 \mu \mathrm{m}$ and $10.1 \mu \mathrm{m}$, respectively. Each QCL modulated the wavelength over a range of about $0.5 \mathrm{~cm}^{-1}$ and acquired an absorption signal with a spectral resolution of about $0.001 \mathrm{~cm}^{-1}$, which corresponded to the laser linewidth. The absorption signal was detected with a non-cooled InAsSb photovoltaic detector. The gas was sampled with a flow rate of approximately $3.3 \mathrm{~L} \cdot \mathrm{min}^{-1}$. The laptop served as the user interface for the operation of the analyser, the calculations, and to display the measured concentrations. In this configuration, the device measurement ranges were 0-1000 ppm for $\mathrm{N}_{2} \mathrm{O}$ and 0-1500 ppm for $\mathrm{NH}_{3}$. The estimated limits of detection (LoDs), 2 times the standard deviation, were $0.04 \mathrm{ppm}$ and $0.06 \mathrm{ppm}$, respectively [10]. The acquisition frequency was $10 \mathrm{~Hz}$. This instrument had been already tested in VELA7 with a compressed natural gas (CNG) vehicle; additional information can be found in [11].

The second instrument was composed of a LAS- $\mathrm{N}_{2} \mathrm{O}$ module and a LAS- $\mathrm{NH}_{3}$ module from AIP automotive, based on laser absorption spectrometry (LAS). The modules used an interband cascade laser (ICL) to analyse $\mathrm{N}_{2} \mathrm{O}$ and a QCL to analyse $\mathrm{NH}_{3}$. The modules quantified the gas concentration by infrared light absorbed by molecules. The analysers performed with high-precision and time-resolved and cross-sensitivity-free measurement in undiluted vehicle exhaust gases.

The setup consisted of five main elements: a sampling probe, the two analyser modules, a Li-ion battery pack module, and a laptop, hosting the user interface. The sampling probe used in this setup had a length of $5 \mathrm{~m}$ consisting of a PTFE inner tube and a sample gas splitter that included a ceramic filter and a pressure regulator, which could regulate up to 4 bar absolute. The sampling probe was heated at $190^{\circ} \mathrm{C}$ in order to ensure no condensation, fast reaction time, and low adsorption effects. The heated and filtered sample was directed in a specifically designed Herriott cell, with an optical path length of $2.1 \mathrm{~m}$, which was operated at $190{ }^{\circ} \mathrm{C}$ and $20 \mathrm{kPa}$. The analysers' measurement ranges were $0-1000 \mathrm{ppm}$ for $\mathrm{N}_{2} \mathrm{O}$ and 0-2000 ppm for $\mathrm{NH}_{3}$. The LoD, defined as 2 times the standard deviation, was $\leq 0.1 \mathrm{ppm}$ for $\mathrm{N}_{2} \mathrm{O}$ and $\leq 0.1 \mathrm{ppm}$ for $\mathrm{NH}_{3}$. The acquisition frequency was $10 \mathrm{~Hz}$. Additional information can be found in Table S2 in Supplementary Materials.

\subsection{On Board Sensors}

The instrumentation of the exhaust line is shown in Figure S1. Given the prototype demonstration status, a large number of exhaust sensors measuring temperatures, pressures, $\mathrm{NOx}$, and $\mathrm{NH}_{3}$ was present. The $\mathrm{NOx}$ sensor specification matched the maturity and accuracy for current production vehicles. The temperature, pressure, and $\mathrm{NH}_{3}$ sensors are devices used for development purposes. Whilst most sensors are used for monitoring purposes only, the NOx sensors upstream the ccDOC (representing the engine-out emissions) and upstream the DOC in the emission control box (representing the NOx emissions into the downstream SCR), as well as the temperature sensors upstream of both urea dosing valves, are used for active control of the urea dosing. The sensors' operating principles and measurement accuracies are those of commercially available units. 


\subsection{Evaluation Methodology}

For all the tests, tailpipe mass emissions were calculated using the exhaust flow resulting from the subtraction of the measured dilution air to the constant flow measured at the CVS. This approach was also used when emissions factors were calculated using the concentrations read by onboard sensors. $\mathrm{SPN}_{23}$ and $\mathrm{SPN}_{10}$ emissions were calculated using the total CVS flow and the Particle Correction Reduction Factor (PCRF) (of $30 \mathrm{~nm}$, $50 \mathrm{~nm}$, and $100 \mathrm{~nm}$ ) according to the Regulation [3]. SPN ${ }_{10}$ was corrected for additional particle losses due to diffusion at the sampling point, as it was sampling from the secondary outlet of the instrument and not from the internal position as the $23 \mathrm{~nm}$ counter [12]. Specifically, for the sub- $23 \mathrm{~nm}$ particles, $\mathrm{SPN}_{10}-\mathrm{SPN}_{23}$, we calculated $20 \%$ more losses than those considered in the PCRF and we corrected accordingly the results. For gaseous pollutants, no corrections were applied.

The tests performed were divided in two different categories on the basis of the amount of work performed during the cycle: "short tests", when the total amount of work was below 3 times the reference work performed in the WHTC at TA; and "long tests", in all other cases. In the following, test length was always used to indicate the amount of work performed during the cycle, while reference work always indicated the work performed during the WHTC at TA.

Depending on the length of the test considered, two distinct evaluation methods to compute emission factors were used. For short tests, emissions factors were computed by simply dividing the cumulative emissions (in $\mathrm{g}$ or number of particles) by the multiplication of reference work by the integer number of times a work equal to the reference work was performed in that test (i.e., 1, 2, or 3), as shown in Equation (1).

$$
\text { emission }_{\mathrm{i}}=\frac{\text { total mass }_{\mathrm{i}}}{\mathrm{k} \times \mathrm{W}_{\text {ref WHTC }}} \text { with } \mathrm{k}=\operatorname{trunc}\left(\frac{\mathrm{W}_{\text {cycle }}}{\mathrm{W}_{\text {ref, } \text { WHTC }}}, 0\right)
$$

All the lengths of short tests performed in this campaign at maximum slightly exceeded 1 times the reference work in the WHTC, as also summarised in Table S3 from Supplementary Materials. For this reason, for such experiments, emissions are always presented as emissions in the first WHVC, i.e., emissions occurring in the test up to a work equal to that done in a single WHTC at TA.

In all other cases, moving windows (MWs) of length equal to the reference work were computed, starting from the beginning of the test and moving with time increments of $1 \mathrm{~s}$, without any exclusion criteria (e.g., for average power). This was at variance with what is currently specified in regulation 595/2009 [3] and subsequent amendments. Such an approach implied that each window had, in this specific case, a length of $29.4 \mathrm{kWh}$ and started $1 \mathrm{~s}$ after the previous one in terms of time. It should be noticed that each window may have had in principle a different time duration. Once all the windows were determined, the 100th and 90th percentiles of the cumulative windows distribution were computed and reported.

Simple descriptive statistic tools such as box plots were used to present aggregated data. In general, for all box plots, the boxes in the plots extended from the first (Q1) to the third quartile (Q3) of the data distribution (also called InterQuartile Range (IQR)), with the horizontal line at the median (Q2). The whiskers extended no more than 1.5 times the difference between the third and first quartile from the edges of the box, ending at the farthest data point within that interval. Outliers were plotted as separate dots and represented measurements falling outside the boundaries identified by upper and lower whisker limits [13]. It should be emphasised that outliers were actual emissions, but due to the extreme conditions, fell far away from the median. A table summarising the results used to construct such plots can be found in Table S4 in Supplementary Materials. All data post processing and visualisation were obtained through custom scripts based on open source language and libraries (PYTHON 3.6, NumPy 1.16.4, Matplotlib 3.1.1, Pandas 1.0.3). 


\section{Results and Discussion}

\subsection{Overall Performance of the Vehicle for Selected Pollutants}

Figure 1 shows the aggregate results of the whole set of tests in the different conditions explored, calculated according to the procedure described in the "Evaluation Methodology" Section 2.5. Before proceeding with the discussion, it is important to point out that Figure 1 gives an overall picture of the emission performances of the vehicle without any ambition of being statistically representative, given the limited number of tests and the multiplicity of effects considered. It should be regarded as an indication of the emissions variability within loosely defined boundaries for operative conditions. It is also worth noting that the tests conducted did not cover all the possible conditions of use of this vehicle.
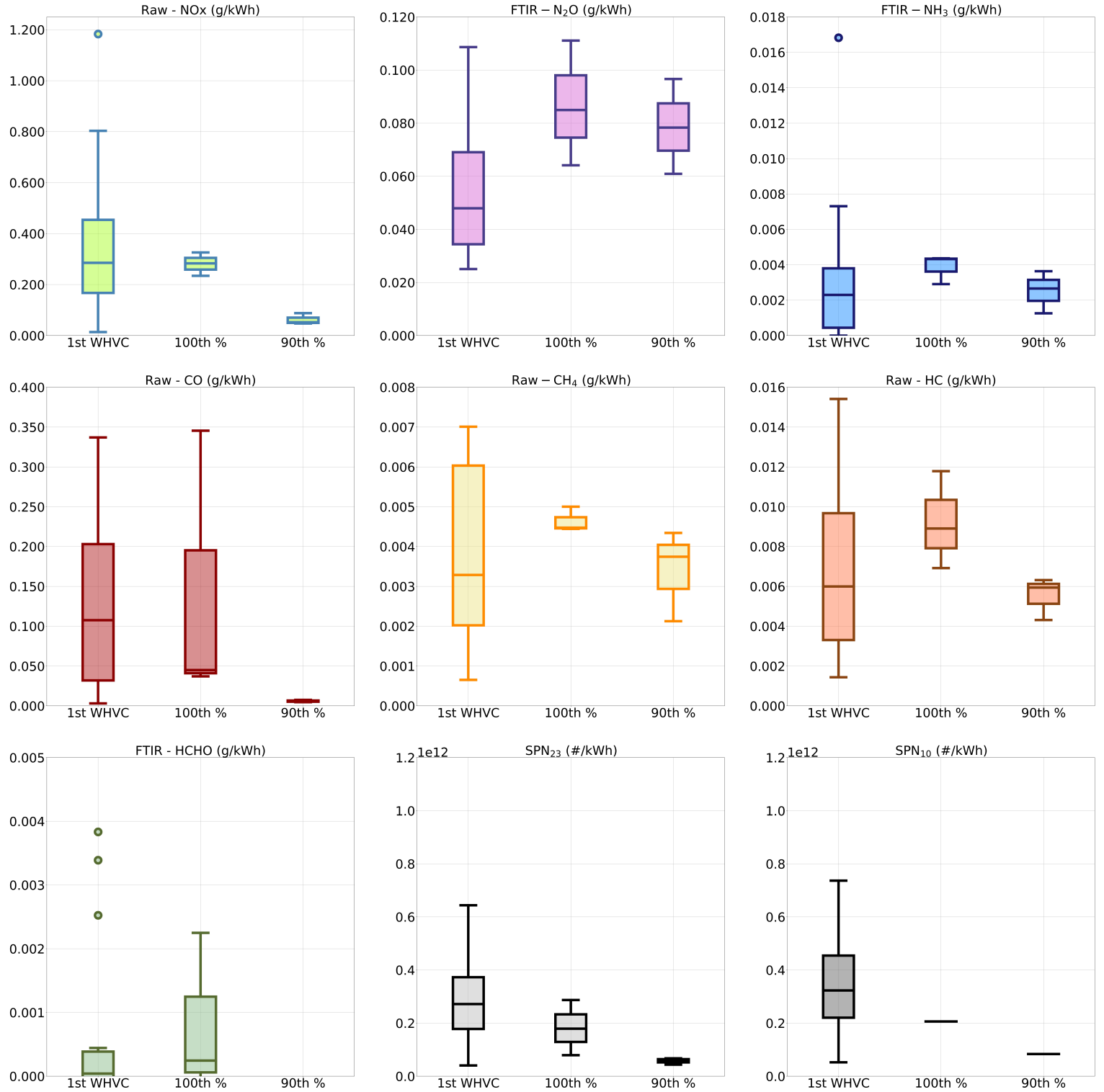

Figure 1. Overall emissions of the complete set of tests. The first WHVC refers to the emissions produced up to the moment in which the total work in a short cycle equals 1 times the reference work in the WHTC. The 90 th $\%$ and 100 th $\%$ refer to the percentiles of the cumulative distribution of work-based MW for long tests, i.e., those whose length exceeded 3 times the reference work. Note that the $\mathrm{SPN}_{10}$ was available only for one test at the long run tests. All gaseous emissions reported were measured at the tailpipe. See "Evaluation Methodology" Section 2.5 for details on the evaluation process. 
From the analysis of Figure 1, it is evident that the overall emissions of $\mathrm{NH}_{3}, \mathrm{CH}_{4}, \mathrm{HC}$, $\mathrm{HCHO}$ are generally low, with very few cases in which $10 \mathrm{mg} / \mathrm{kWh}$ are exceeded. For this reason, in the following, the discussion focuses on the other pollutants, although all the data measured are available in Supplementary Materials for reference. It should be noted that, as already discussed in the "Evaluation Methodology" Section 2.5, no correction was performed for any of the instruments used in the campaign and, in this respect, all the data herein reported are to be considered "as measured". It can be also noticed that $\mathrm{SPN}_{23}$ and $\mathrm{SPN}_{10}$ emissions are similar, with an additional fraction due to finer particles in the order of 15-25\%; see also the detailed analysis in Figure S4 in Supplementary Materials. For this reason, in the following sections, the analysis focuses on $\mathrm{NOx}, \mathrm{N}_{2} \mathrm{O}, \mathrm{CO}$, and $\mathrm{SPN}_{23}$, for which considerations will be less influenced by the experimental error, due to the higher quantities measured and due to the availability of $\mathrm{SPN}_{23}$ for more tests (as detailed in the "VELA7 Heavy-Duty Test Cell" Section 2.2). In addition, the latter was less influenced by the experimental uncertainties due to possible interference from volatiles [14] as the system had an evaporation tube and not a catalytic stripper.

The median of NOx emissions in the short tests was in the order of $285 \mathrm{mg} / \mathrm{kWh}$, with, however, a high variability $(14-803 \mathrm{mg} / \mathrm{kWh})$ in the emissions performances. A high emissions test of $1183 \mathrm{mg} / \mathrm{kWh}$ was also recorded in a low load urban test at $-7^{\circ} \mathrm{C}$. This is discussed in more detail in the "Effect of Usage Patterns" Section 3.5 below. Generally speaking, long tests show comparable NOx emissions for the worst window (i.e., 100th cumulative percentile). The median for the 100th percentile of the MW cumulative distribution was $283 \mathrm{mg} / \mathrm{kWh}$, with a much lower variability (235-326 mg/kWh). This was due to the fact that the long tests category included only three RWT cycles at different ambient temperature conditions $\left(-7^{\circ} \mathrm{C}\right.$ up to $35^{\circ} \mathrm{C}$ ) with fixed $10 \%$ payload. Interestingly, the variability, which was induced only by temperature in this case, was minor. Moreover, the evaluation approach using MW allows granularity in the assessment of emissions. It isolates single high emitting events (included in the 100th and above the 90th percentiles) from a generally well-behaved average performance (ideally expressed by the 90th percentile). For this specific vehicle, the worst windows were always registered during cold start, when the emission control system was still cold an unable to effectively reduce NOx, as can be also graphically seen in Figure S5 in Supplementary Materials. Interestingly, for such cycles, very low NOx emissions could be still achieved for most of the cycle, with a 90th percentile of the windows distribution of $52 \mathrm{mg} / \mathrm{kWh}$, with variability between $51 \mathrm{mg} / \mathrm{kWh}$ and $88 \mathrm{mg} / \mathrm{kWh}$.

Qualitatively similar situations could be described for $\mathrm{SPN}_{23}$ and $\mathrm{SPN}_{10}$ with higher variability in shorter tests and decreasing emissions going from the 100th to the 90th cumulative percentiles of the MW distribution in long tests. A summary table reporting emissions results for all pollutants can be found in Table S3.

The median $\mathrm{SPN}_{23}$ emissions for all performed tests was $2.71 \times 10^{11} \mathrm{\#} / \mathrm{kWh} . \mathrm{SPN}_{23}$ varied between $4.03 \times 10^{10} \# / \mathrm{kWh}$ and $6.61 \times 10^{11}$ \#/kWh. On average, $\mathrm{SPN}_{10}$ was $19 \%$ higher than $\mathrm{SPN}_{23}$, this value varying from $15 \%$ to $29 \%$. Note that $\mathrm{SPN}_{10}$ was measured only for one out of three RWT cycles due to data logging issues. An overview of solid particle number emissions for each test can be found in Figure S4 in Supplementary Materials. Similar to NOx, at shorter cycles, higher variability of solid particle number emissions was observed, with decreased emissions going from 100 th $\left(>1 \times 10^{11} \# / \mathrm{kWh}\right)$ to the 90 th $\left(<9 \times 10^{10} \# / \mathrm{kWh}\right)$ cumulative percentiles of the MW distribution in long tests at all temperature conditions $\left(-7^{\circ} \mathrm{C}, 23^{\circ} \mathrm{C}, 35^{\circ} \mathrm{C}\right)$.

$\mathrm{N}_{2} \mathrm{O}$ and $\mathrm{NH}_{3}$, despite the very low emissions of the latter, showed a different trend. Indeed, emissions factors were comparable in both short and long tests, without a clear distinction between the 100th and 90th percentiles. The median $\mathrm{N}_{2} \mathrm{O}$ emissions for short tests were in the order of $42 \mathrm{mg} / \mathrm{kWh}$, with variability between $10 \mathrm{mg} / \mathrm{kWh}$ and $109 \mathrm{mg} / \mathrm{kWh}$. Long test emissions for the 100th and 90th cumulative percentiles were, respectively, $85 \mathrm{mg} / \mathrm{kWh}$ (variation 64-111 mg/kWh) and $78 \mathrm{mg} / \mathrm{kWh}$ (variation 61-97 mg/kWh). This indicates fairly continuous and low emissions, without significantly different events in 
the cycle such as cold start vs. stabilised hot emissions. This is in line with what was already reported in the literature $[2,15]$ and consistent with possible pathways for $\mathrm{N}_{2} \mathrm{O}$ production in Diesel emission control systems. Indeed, these are nowadays characterised by the requirement for very low NOx tailpipe emissions, requiring active DOCs, and an increase in the DEF injection rates together with the necessity of limiting any $\mathrm{NH}_{3}$ slip at the tailpipe.

$\mathrm{CO}$ emissions were in the range of $0-350 \mathrm{mg} / \mathrm{kWh}$ in both short and long tests. The 90th cumulative percentile of the distribution of the windows was essentially close to zero. This indicated a very sharp and quickly decreasing distribution or, in other words, that for the tested system, most of the emissions were produced during cold start events.

$\mathrm{HCHO}$ emissions were very low and in the range of the experimental error of the instrument for all the tests considered and for this reason will be not discussed further. However, it is important to keep in mind that the measurement of aldehydes is generally complex [16]. Additional work will be needed to properly assess HCHO emissions from next generation vehicles.

\subsection{Comparison with Euro VI step C Vehicle}

Figure 2 reports a comparison between a Euro VI step C vehicle and the vehicle object of this study. Note that for each pollutant, right panels include the same data already discussed in the previous section and are herein reported only for ease of comparison.

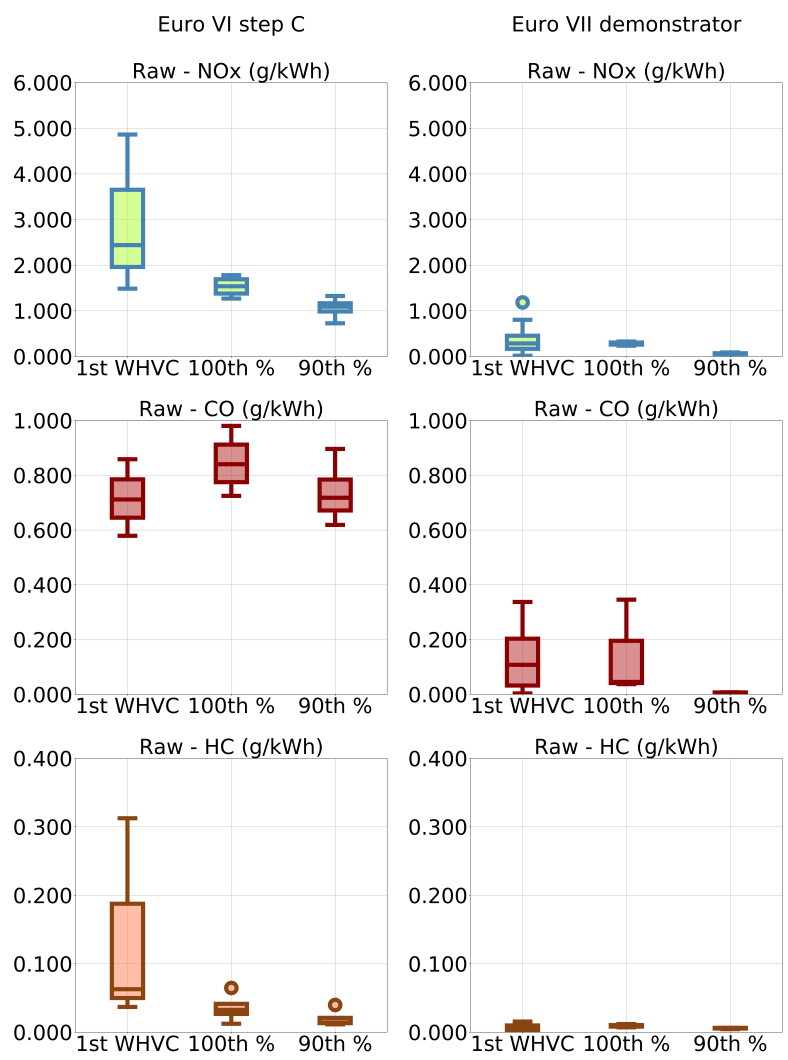

Figure 2. Overall emissions of a Euro VI step C vehicle (left panels for each pollutant) and the Euro VII (right panels for each pollutant) demonstrator vehicle. The vehicles were tested on not directly comparable roads; see details in the "Vehicle and Tests" Section 2.1. The first WHTC refers to the emissions produced up to the moment in which the total work in a short cycle equals 1 times the reference work in the WHTC. The 90 th $\%$ and 100 th $\%$ refer to the percentiles of the cumulative distribution of work-based MW for long tests, i.e., those whose length exceeded 3 times the reference work. All gaseous emissions reported were measured at the tailpipe. See the "Evaluation Methodology" Section 2.5 for details on the evaluation process. 
Although the Euro VI step C vehicle is not a "new" vehicle, and similar data could be found in the literature [2], the dataset herein reported was processed according to the same new method firstly introduced in this work and described in the "Evaluation Methodology" Section 2.5. Nevertheless, the test cycles performed in the two data set were not the same, even if they both comprised examples of simulated road driving in representative conditions. Additional information on the different routes and road gradients can be found in the "Vehicle and Tests" Section in Supplementary Materials.

Although mainly qualitative due to the limitations just described, this comparison shows an evident improvement in emission performances for all the pollutants considered, in line with what was also reported in [2] and in accordance to the evolution of air pollution regulations in Europe.

In particular, NOx emissions were reduced by approximately 9, 5, and 21 times for the short tests and the 100th and 90th cumulative percentiles of long tests, respectively. The variability was also drastically reduced, suggesting an increased robustness to varying operative conditions, especially considering that none of the Euro VI step C tests were carried out at sub-zero temperatures.

Similar reductions were seen in the case of $\mathrm{HC}$ emissions, with a decrease of the emissions of 12,3 , and 2 times in the same three cases.

Even more consistent improvements were achieved in the case of $\mathrm{CO}$, with reduction of approximately 6, 19, and more than 2 orders of magnitude for short tests and the 100th and 90th cumulative percentiles of longer tests, respectively. These figures are in line with what was reported in literature, although it must be noted that the comparison was not done in perfectly comparable conditions, as already discussed [2,17-19].

\subsection{Effects of Temperature}

Figure 3 shows the effects of test temperature on the emissions of selected pollutants during cold RWT conducted at $10 \%$ simulated payload with a conditioned emission control system.

First of all, as expected, colder temperatures had a detrimental effect on the emissions of NOx. Total emissions increased from 9 to $11 \mathrm{~g}$ by changing ambient temperature from $35^{\circ} \mathrm{C}$ to $-7{ }^{\circ} \mathrm{C}$, especially due to a more pronounced and extended cold start, as can be seen from instantaneous emissions profiles. This was mostly related to the increased difficulty in heating up quickly the SCR units and to reach the target temperature for DEF injection in colder conditions. In this respect, is also important to note that the test was started immediately after having switched on the engine, with no warming up period.

The situation was qualitatively similar for $\mathrm{CO}$, in which however the impact of low temperature was much more pronounced. Indeed, colder emissions at $-7^{\circ} \mathrm{C}$ were approximately one order of magnitude larger with respect to those in milder conditions $(10.5 \mathrm{~g}$ at $-7{ }^{\circ} \mathrm{C}$ vs. $1.5 \mathrm{~g}$ at $35^{\circ} \mathrm{C}$ ). Additionally, in this case, high cold start emissions were predominant and likely related to inactive catalysts due to low temperature. It is important to mention that, in this period, emissions were essentially uncontrolled and equal to engine out emissions.

Interestingly, the situation was different for $\mathrm{N}_{2} \mathrm{O}$ in which the impact of temperature was much less pronounced (overall emissions were between $5.7 \mathrm{~g}$ and $6.9 \mathrm{~g}$ for the temperatures tested) and with a very different emissions trend. Cold start was no more predominant, with instead continuous emissions throughout the test. This was already evident from the distribution of the 100th and 90th cumulative percentiles reported in Figure 1, and it is an indication of the different formation pathways with respect to other $\mathrm{N}$-containing compounds (e.g., $\mathrm{NOx}$ ). A more detailed discussion related to $\mathrm{N}_{2} \mathrm{O}$ is done in the following sections. 

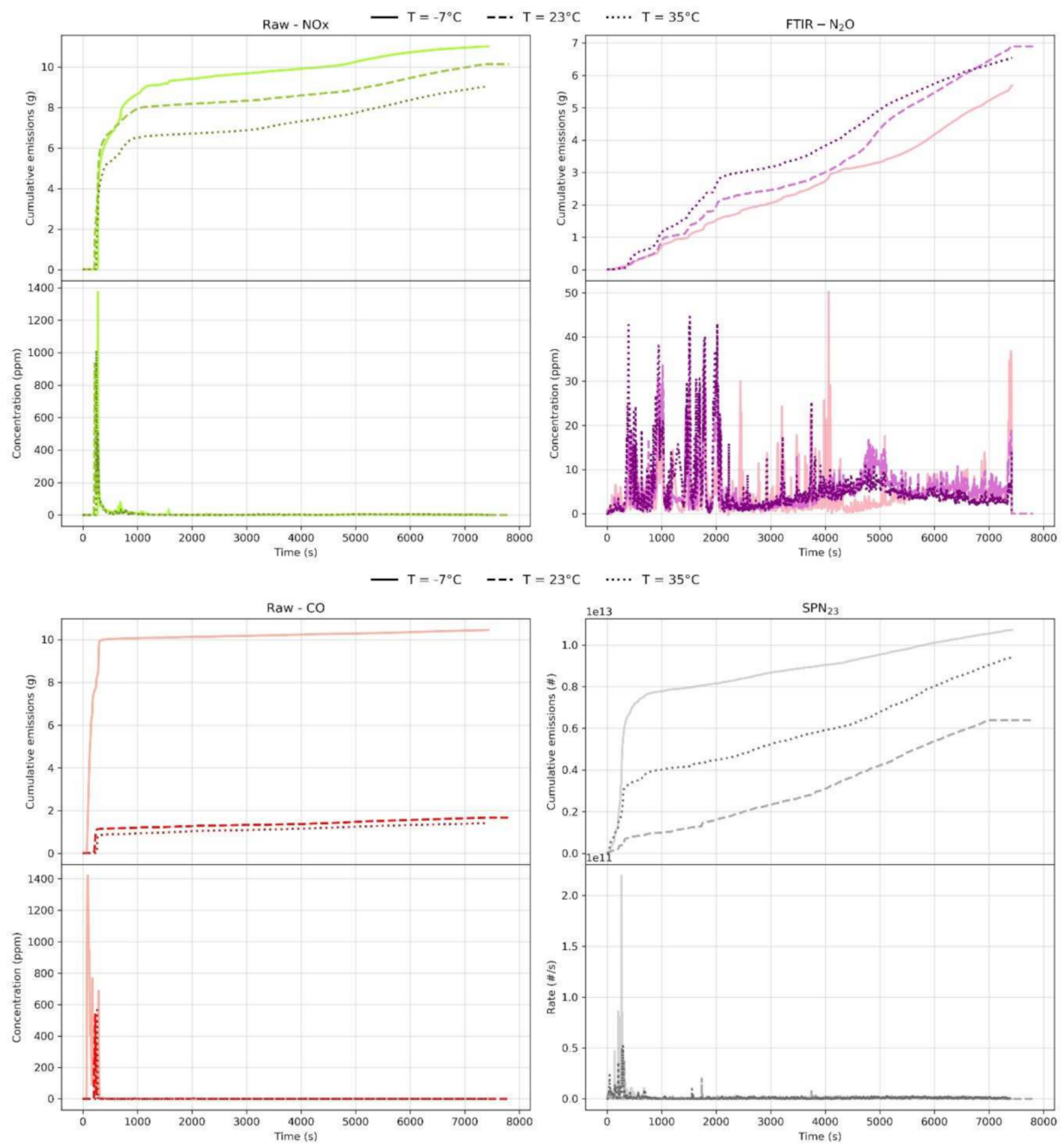

Figure 3. Effect of temperature on the emissions of selected pollutants $\left(\mathrm{NOx}, \mathrm{N}_{2} \mathrm{O}, \mathrm{CO}, \mathrm{SPN}_{23}\right)$ in the cold RWT at $10 \%$ payload with a conditioned emission control system. For each pollutant, the top panel reports cumulative emissions ( $\mathrm{g}$ or \#), while the lower panel instantaneous emissions (ppm or \#/s) at three different temperatures: solid line $-7{ }^{\circ} \mathrm{C}$, dashed line $23^{\circ} \mathrm{C}$, and dotted line $35^{\circ} \mathrm{C}$. All gaseous emissions reported were measured at the tailpipe. See the "Evaluation Methodology" Section 2.5 for details on evaluation procedure.

No clear temperature effect was observed for $\mathrm{SPN}_{23}$. At $-7{ }^{\circ} \mathrm{C}$ and at $35^{\circ} \mathrm{C}$, the cumulative $\mathrm{SPN}_{23}$ emissions (\#) were $24 \%$ and $15 \%$ higher than at $23{ }^{\circ} \mathrm{C}$, respectively, with the differences originating from some spikes during the cold start. Specific $\mathrm{SPN}_{23}$ emissions $(\# / \mathrm{kWh})$ are presented in the Supplementary Information (Figure S4) and are calculated according to the approach described in the "Evaluation Methodology" Section 2.5. It can be noticed that the worst windows (i.e., the 100th cumulative percentiles) at $-7^{\circ} \mathrm{C}$ and $35{ }^{\circ} \mathrm{C}$ were $107 \%$ and $28 \%$ higher, respectively, with respect to the $23{ }^{\circ} \mathrm{C}$ case. The 90 th cumulative percentiles were comparable for the $23{ }^{\circ} \mathrm{C}$ and $35^{\circ} \mathrm{C}$ cases $(2 \%$ difference $)$ and 
$37 \%$ lower when comparing $-7^{\circ} \mathrm{C}$ to $23^{\circ} \mathrm{C}$. SPN 10 data were available only for the test performed at $35^{\circ} \mathrm{C}$, and it was $20 \%$ higher than $\mathrm{SPN}_{23}$.

\subsection{Effect of Payload}

Figure 4 shows the effect of payload on the emissions of selected pollutants during cold urban delivery cycles conducted at $-7^{\circ} \mathrm{C}$ with a conditioned emission control system.
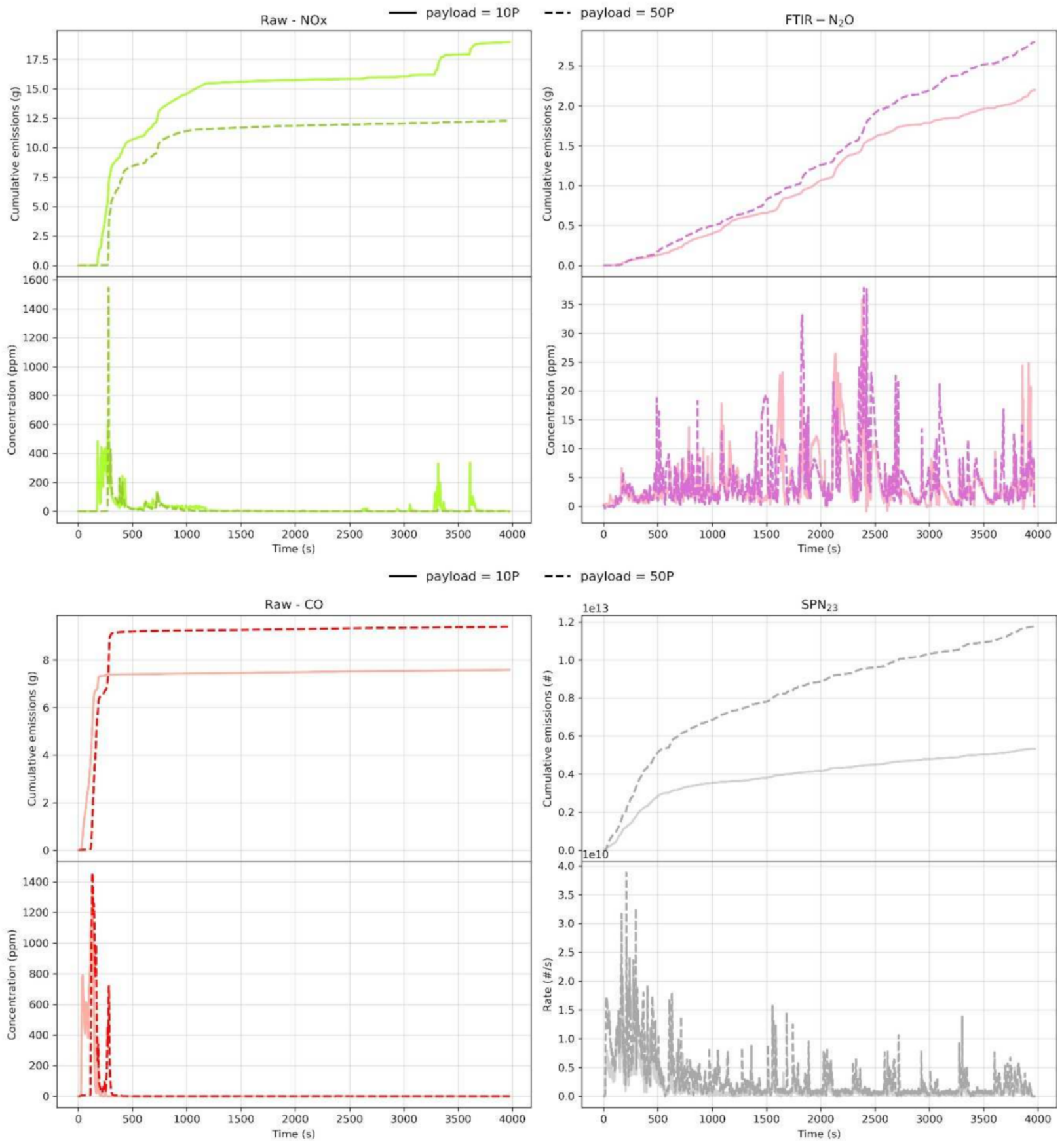

Figure 4. Effect of payload on the emissions of selected pollutants $\left(\mathrm{NOx}, \mathrm{N}_{2} \mathrm{O}, \mathrm{CO}, \mathrm{SPN}_{23}\right)$ in cold urban delivery cycles at $-7{ }^{\circ} \mathrm{C}$ with a conditioned emission control system. For each pollutant, the top panel reports cumulative emissions ( $\mathrm{g}$ or \#), while the lower panel instantaneous emissions (ppm or \#/s) at two different payloads: solid line 10\%, dashed line 50\%. All gaseous emissions reported were measured at the tailpipe. See the "Evaluation Methodology" Section 2.5 for details on evaluation procedure. 
First of all, for NOx emissions, lower payloads had detrimental effects on emissions; at $10 \%$ payload, overall emissions were $19 \mathrm{~g}$, while at $50 \%$, they were $12.3 \mathrm{~g}$. By inspecting the emissions profiles, it can be assumed that this was again due to the increased difficulty in quickly heating up the catalytic system and in maintaining the temperature during low load operations at such low temperatures and with a lower vehicle load. Indeed, at $10 \%$ payload, the cold start emissions had lower peaks but a more pronounced duration in time, and, at the end of the cycle (approximately at 3200 s), additional NOx were released. As can be also seen in Figure S2 in Supplementary Materials, this occurred after a sequence of prolonged idling phases of $3 \mathrm{~min}$. This assumption was confirmed by the temperature profiles of the emission control system in the two cases (see Figure S6 in Supplementary Materials) where it is evident that a lower temperature was registered for the $10 \%$ case.

The situation was qualitatively reversed for $\mathrm{CO}$. In this case, emissions were better controlled at lower payloads (7.6 g vs. $9.4 \mathrm{~g}$ ). From the emissions profiles, it seems that this was due to a single event during cold start, a second peak at $250 \mathrm{~s}$ approximately. It is unclear whether this was due to an additional load required to the engine or to a slight variability in test execution, despite the faster heat up of the emission control system and of the DOC in particular.

$\mathrm{N}_{2} \mathrm{O}$ emissions were again not significantly affected by the change in payload (total emissions were within $0.5 \mathrm{~g}$ in the two cases). This suggests that the control strategy of the emission control system was not significantly different in the two cases, resulting in a similar situation from a catalytic point of view. This in line again with the fact that $\mathrm{N}_{2} \mathrm{O}$ formation was mostly related to the occurrence of unselective catalytic reactions and was not significantly affected by the engine behaviour.

Finally, for SPN, the situation was in line with that already described for CO. Emissions were more pronounced in the case of higher payloads $\left(1.2 \times 10^{13} \#\right.$ vs. $\left.5.3 \times 10^{12} \#\right)$, possibly due to the higher engine demand. When comparing specific $\mathrm{SPN}_{23}$ emissions (\#/kWh) calculated according to the approach described in the "Evaluation Methodology" Section 2.5, it can be noticed that at higher load they were $75 \%$ more. This finding is in agreement with previous studies that observed increased particulate mass [20] and particle number emissions [21] for higher loads of a heavy-duty diesel truck and bus, respectively. $\mathrm{SPN}_{10}$ emissions were $25 \%$ higher than $\mathrm{SPN}_{23}$ at $10 \%$ payload and $20 \%$ at $55 \%$ payload.

\subsection{Effect of Usage Patterns}

Figure 5 shows the effect of the utilisation pattern on the emissions of selected pollutants, using $10 \%$ payload, at an ambient temperature of $-7^{\circ} \mathrm{C}$, with conditioned emission control system, and in cold starting conditions. Details on the three cycles considered here are reported in Figure S2 in Supplementary Materials and are summarised in the following for convenience.

The JRC cycle is characterised by a very low load, with maximum speed hardly exceeding $40 \mathrm{~km} / \mathrm{h}$ and multiple stops of different duration up to $3 \mathrm{~min}$. This was used to simulate the behaviour of an urban bus moving in a city and thus not representative of a N3 vehicle's normal use, although in principle the same engine could be mounted also on a bus. The urban cycle is also a low load cycle with, however, higher maximum speed of $50 \mathrm{~km} / \mathrm{h}$, longer driving intervals, and fewer and shorter stops. This was used to simulate a delivery truck in a city environment. The RWT is a test that comprises urban, rural, and motorway sections, with maximum speed exceeding $80 \mathrm{~km} / \mathrm{h}$, varying road gradients, and few stops. This was used to simulate the real-world usage of a long haul truck, which is more similar to the design operation of the vehicle under test. Notice that urban and RWT cycle emissions are those already described in previous sections and are herein reported just for comparison purposes and not discussed again. 

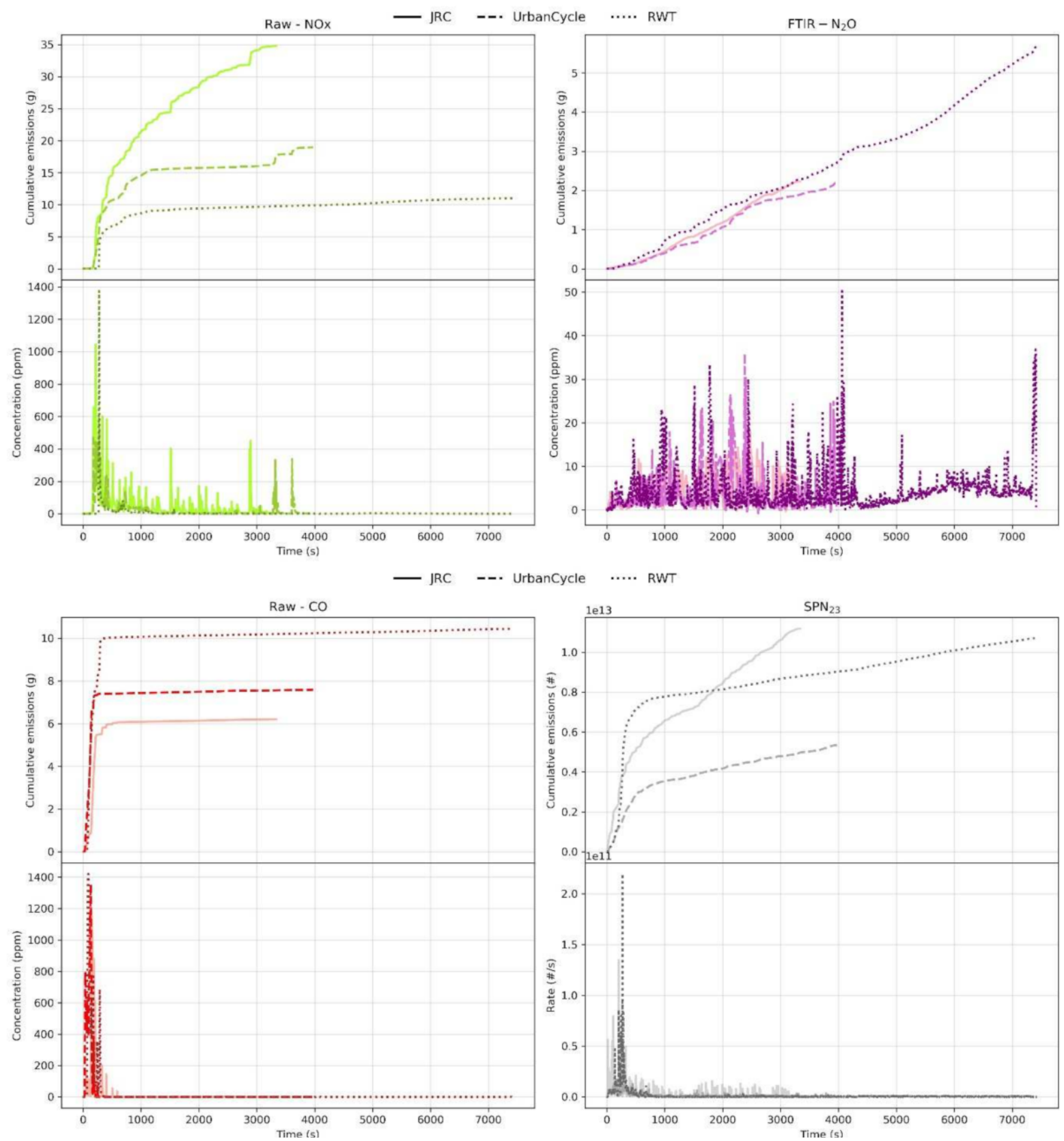

Figure 5. Effect of usage patterns on the emissions of selected pollutants ( $\mathrm{NOx}, \mathrm{N}_{2} \mathrm{O}, \mathrm{CO}, \mathrm{SPN}_{23}$ ) at $-7{ }^{\circ} \mathrm{C}$, with $10 \%$ payload, conditioned emission control system, and in cold starting conditions. For each pollutant, the top panel reports cumulative emissions ( $\mathrm{g}$ or \#), while the lower panel instantaneous emissions (ppm or \#/s) in three different usage conditions: solid line JRC city drive, dashed line urban delivery cycle, dotted line real world test. All gaseous emissions reported were measured at the tailpipe. See the "Evaluation Methodology" Section 2.5 for details on evaluation procedure and Figure S2 in Supplementary Materials for details on usage conditions.

As expected, the JRC cycle was the most demanding in terms of NOx emissions due to the extremely low temperature and load. By the inspection of OBD readings and temperature profiles, it has indeed been confirmed that the DEF dosage unit never worked throughout the whole test (see Figure S7 in SI). This resulted in very high tailpipe emissions in line with those registered at engine out, reaching almost $35 \mathrm{~g}$ in total despite the short duration.

It is again interesting to notice how the situation for $\mathrm{CO}$ was qualitatively opposite with respect to NOx. Indeed, cycles with more demanding cold starts in terms of engine 
requirements resulted in higher emissions, while the JRC cycle, due to its very low load, resulted in only $6 \mathrm{~g}$ of total emissions. This was also in line with the effect of payload previously discussed.

$\mathrm{N}_{2} \mathrm{O}$ emissions were essentially independent from the usage pattern, with differences in total emissions only related to the different test length. While a detailed discussion on the different chemistries leading to $\mathrm{N}_{2} \mathrm{O}$ production is beyond the scope of this work, it is important to recall that nitrous oxide can be formed due to (i) unselective reaction between $\mathrm{NH}_{3}$ and $\mathrm{NO}_{2}$ on zeolite catalysts leading to formation and decomposition of nitrates [22]; and (ii) unselective $\mathrm{NH}_{3}$ oxidation on ASC [23]; and (iii) as a by-product of NOx reduction by HC on DOC [24]. Importantly, all the above-mentioned mechanisms have distinct and hardly overlapping temperatures windows [24] requiring a complex and global optimisation of the whole emission control system. The theoretical absence of $\mathrm{NH}_{3}$ in the system during the JRC cycle, due to the low emission control system temperature preventing DEF injection and to the preconditioning procedure consuming stored $\mathrm{NH}_{3}$ and carried out the day before starting the test, suggests that the main production mechanism of $\mathrm{N}_{2} \mathrm{O}$ in this vehicle was the one related to unselective NOx reduction by $\mathrm{HC}$ on the DOC. It is also worth mentioning that the temperature window for such a mechanism is consistent with what is indicated in [24] and measured for the system under test (see Figure S7 in Supplementary Materials). In any case, this behaviour will require additional investigation and it is an interesting point to keep in mind for system optimisation. In addition, this suggests that a complex interplay might exist between $\mathrm{NOx}, \mathrm{N}_{2} \mathrm{O}$, and $\mathrm{CO} / \mathrm{HC}$ emissions at least for the emission control system configuration studied.

$\mathrm{SPN}_{23}$ emissions trends were different for the three cycles. While at the RWT and the urban cycle, cold start emissions dominated the total emitted particles ( $>60 \%$ during the first $500 \mathrm{~s}$ ), this was not the case for the JRC cycle where $\mathrm{SPN}_{23}$ emissions continued to increase during all its duration. The rationale was that during the JRC cycle, a stop and go cycle, SPN was emitted at each acceleration, and, thus, the cumulative SPN emissions continued to increase.

\subsection{Idling}

Figure 6 shows the emissions of selected pollutants during an idling test at an ambient temperature of $18{ }^{\circ} \mathrm{C}$ without preconditioning the emission control system, and in cold start conditions.

First of all, it is important to notice that the NOx concentration profile exhibited a significant delay of more than $800 \mathrm{~s}$. After that, a large peak of approximately $90 \mathrm{ppm}$ was released. This, as can be also noticed in Figure S8 in Supplementary Materials, incidentally coincided with the breakthrough of $\mathrm{H}_{2} \mathrm{O}$. Indeed, the exothermic stabilisation of $\mathrm{H}_{2} \mathrm{O}$ immediately preceding its slip-on zeolite catalysts is well known to cause such an effect [25]; due to the rapid increase in temperature, desorption of NOx, or decomposition of nitrates can occur. Afterwards, NOx emissions were expected to progressively decrease to levels comparable with engine out steady state emissions. Unfortunately, the test was too short to see such an effect. It is also important to recall that before the test, the catalyst was not preconditioned (and thus adsorbed $\mathrm{NH}_{3}$ should be available) and that the test was started hot, meaning that the emission control system was not completely cold.

The CO profile shows an interesting trend with a delay of approximately $300 \mathrm{~s}$ followed by a peak of more than $250 \mathrm{ppm}$ and a subsequent drop in emissions.

$\mathrm{N}_{2} \mathrm{O}$ emissions showed a peak of $20 \mathrm{ppm}$ right at the very beginning of the test with very low values everywhere else. This initial peak was expected to be related to a continuous $\mathrm{N}_{2} \mathrm{O}$ accumulation in the emission control system during the cool down until the temperature was sufficiently high to promote catalytic reactions, even with engine off. As soon as the engine was re-ignited, the $\mathrm{N}_{2} \mathrm{O}$ accumulated was purged by the exhaust gases flowing through the system, resulting in a peak at test start. The accumulation in the sampling lines was, however, negligible. Indeed, by simply disconnecting them and leaving the instrument sampling, the measured concentration dropped to zero immediately. 

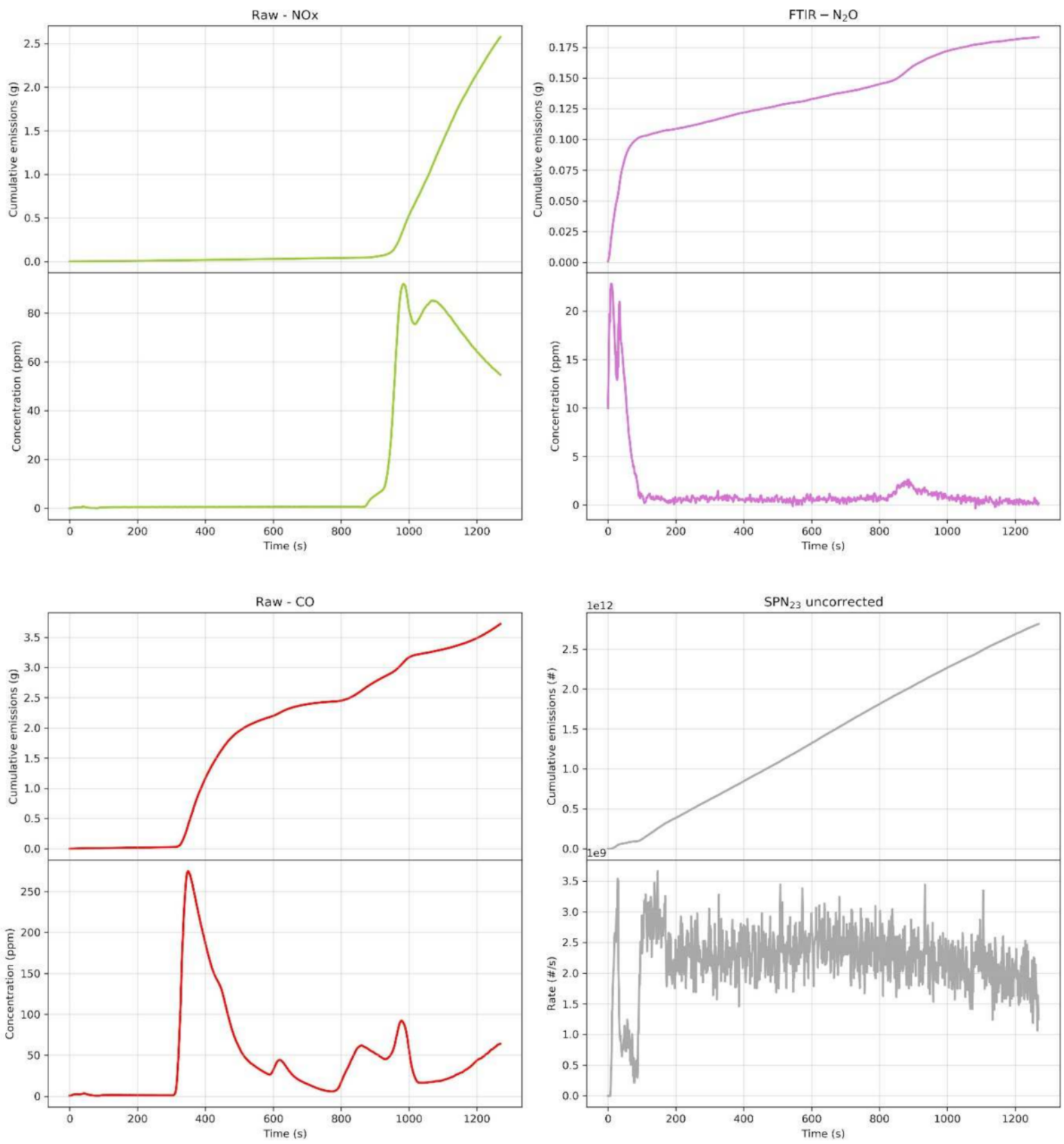

Figure 6. Emissions of selected pollutants ( $\mathrm{NOx}, \mathrm{N}_{2} \mathrm{O}, \mathrm{CO}, \mathrm{SPN}_{23}$ ) during an idling test at $18{ }^{\circ} \mathrm{C}$, with cold engine and not conditioned emission control system. For each pollutant, the top panel reports cumulative emissions (g or \#), the while lower panel instantaneous emissions (ppm or \#/s). All gaseous emissions reported were measured at the tailpipe. See the "Evaluation Methodology" Section 2.5 for details on evaluation procedures.

$\mathrm{PN}$ emissions after the engine ignition and the first $\mathrm{SPN}_{23}$ peak dropped and then increased and stabilised throughout the test in the order of $2.5 \times 10^{9} \# / \mathrm{s}$. This rate corresponded to a tailpipe concentration of $4.5 \times 10^{4} \# / \mathrm{cm}^{3}$. The $\mathrm{SPN}_{10}$ was $\sim 15 \%$ higher than $\mathrm{SPN}_{23}$, and thus the sub-23 nm particle fraction was very low.

\subsection{Effect of Initial Status of the Emission Control System}

Figure 7 shows the impact of the conditioning procedure described in the "Vehicle and Tests" Section 2.1. This consisted of driving the vehicle for approximately $30 \mathrm{~min}$ at high speed $(70 \mathrm{~km} / \mathrm{h})$ with DEF dosing disabled. This promoted a passive regeneration of the DPF, avoided any clogging of the exhaust lines, consuming at the same time the 
$\mathrm{NH}_{3}$ stored on the two SCR units. This also allowed the system to have similar starting conditions for the catalysts.
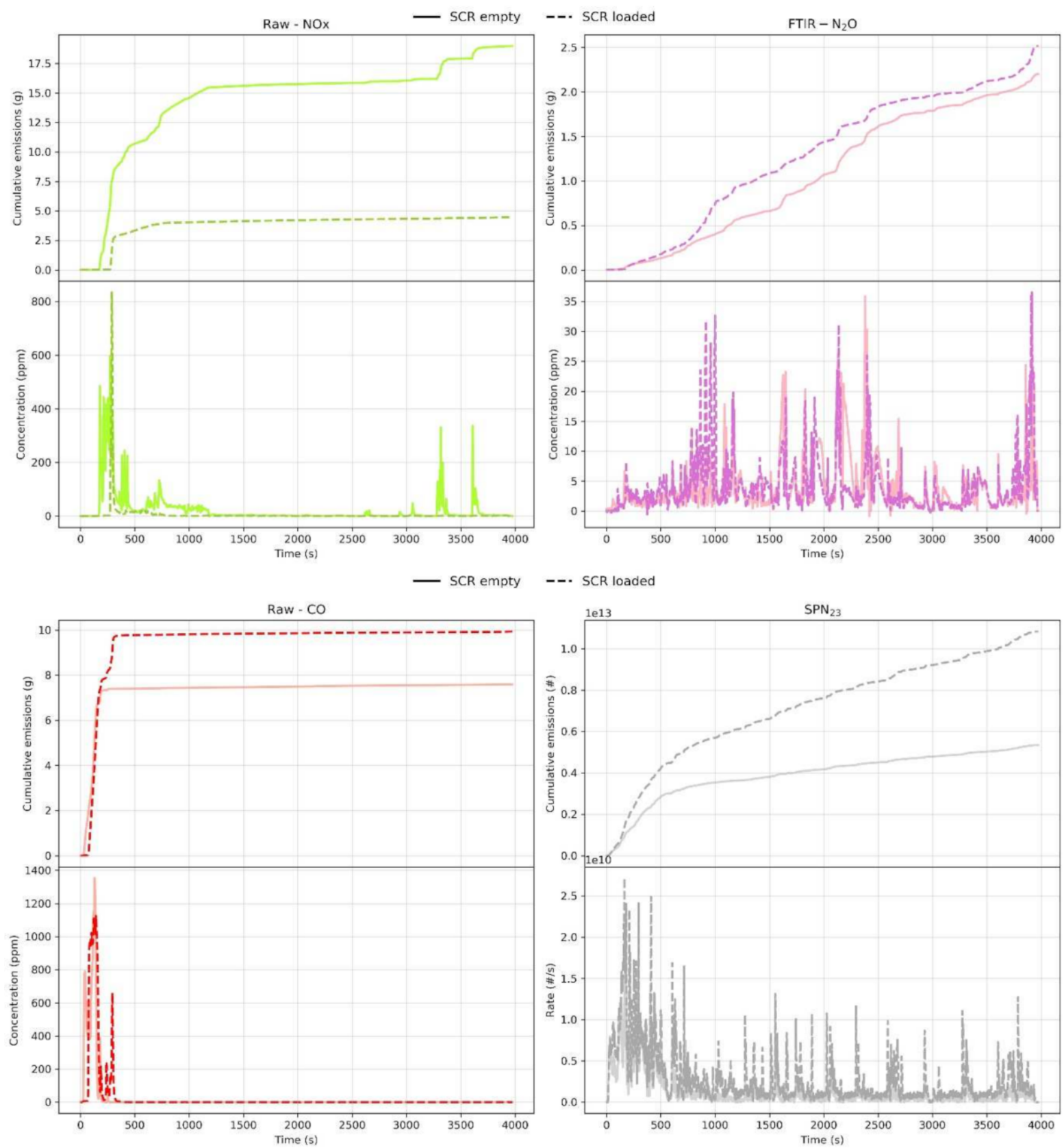

Figure 7. Effect of emission control system conditioning procedure on the emissions of selected pollutants ( $\mathrm{NOx}, \mathrm{N}_{2} \mathrm{O}, \mathrm{CO}, \mathrm{SPN}_{23}$ ) in the urban delivery cycle at $-7^{\circ} \mathrm{C}$ and $10 \%$ payload. For each pollutant, top panel reports the cumulative emissions ( $\mathrm{g}$ or \#), while the lower panel instantaneous emissions (ppm or \#/s) in two emission control system conditions: solid line emission control system conditioned (SCR assumed empty, DPF assumed empty), dashed line emission control system not conditioned (SCR and DPF loading from previous test). All gaseous emissions reported were measured at the tailpipe. See the "Evaluation Methodology" Section 2.5 and "Vehicle and Tests" Section 2.1 for details on evaluation and conditioning procedures.

First, it should be noticed that, as expected, the effect on NOx emissions was significant. Indeed, a side effect of the conditioning procedure, due to the high-speed driving with deactivated DEF injection, was to consume all the $\mathrm{NH}_{3}$ stored on the catalysts. This had the net result of strongly reducing SCR performance during cold start operations due to the 
absence of reactivity at low temperatures and the drastic reduction also of the possibility of storing NOx as nitrates on the catalyst. This was clearly evident inspecting the cumulative emission curves with a total NOx emission of $4.5 \mathrm{~g}$ vs. $19 \mathrm{~g}$ approximately in the two cases. Moreover, due to the average low load of the test, the temperature of the emission control system was generally low, making DEF injection problematic. This was evident in the last part of the test, where, after prolonged idling, additional NOx peaks were released in the case of a preconditioned vehicle. This was an indication also of the importance of a proper optimisation of the emission control system control and injection strategy.

The effect on $\mathrm{CO}$ was much less pronounced and inside the variability of the tests. From the emissions profiles, it seems that this was due to a single event during cold start, the second peak at $250 \mathrm{~s}$ approximately. It is unclear whether this was due an additional load required to the engine due to a slight variability in test execution.

The effect on $\mathrm{N}_{2} \mathrm{O}$ was once again negligible. This was interesting and in line with what was discussed in the "Effect of Usage Patterns". It seems that for this vehicle, the predominant mechanism for $\mathrm{N}_{2} \mathrm{O}$ production was related to unselective reactivity on the DOC and not to routes involving the presence of $\mathrm{NH}_{3}$. Indeed, overall emissions in the two cases matched quite well throughout the test, with an overall amount close to $2.5 \mathrm{~g}$.

No effect of the conditioning was observed for $\mathrm{SPN}_{23}$ and $\mathrm{SPN}_{10}$ emissions. The conditioning cycle should have resulted in a passive regeneration of the DPF and thus a lower efficiency due to the low DPF fill state. There were no OBD data available to confirm whether the filter regenerated. Results indicated that either no regeneration occurred, or the regeneration was such that the DPF fill state was still high enough for the tests performed after it.

\section{8. $\mathrm{CO}_{2}$ Emissions with Contributions from Unregulated Pollutants}

Figure 8 shows the average $\mathrm{CO}_{2}$ emissions of the vehicle in both short and long tests, considering also the contributions of pollutants that, in addition to a negative impact on air quality [26], also promote global warming, namely $\mathrm{N}_{2} \mathrm{O}$ and $\mathrm{CH}_{4}$. However, in this specific case, the $\mathrm{CH}_{4}$ contribution was negligible due to very low emissions, as discussed. From the Figure 8 it is first of all evident that the $\mathrm{N}_{2} \mathrm{O}$ contribution to the $\mathrm{CO}_{2}$ equivalent emissions, considering a global warming potential (GWP) for $\mathrm{N}_{2} \mathrm{O}$ of 298 [27], was relatively small. The increase in $\mathrm{CO}_{2}$ equivalent emissions due to $\mathrm{N}_{2} \mathrm{O}$ was in fact in the order of $2.1-2.7 \%$ for both categories of tests considered.

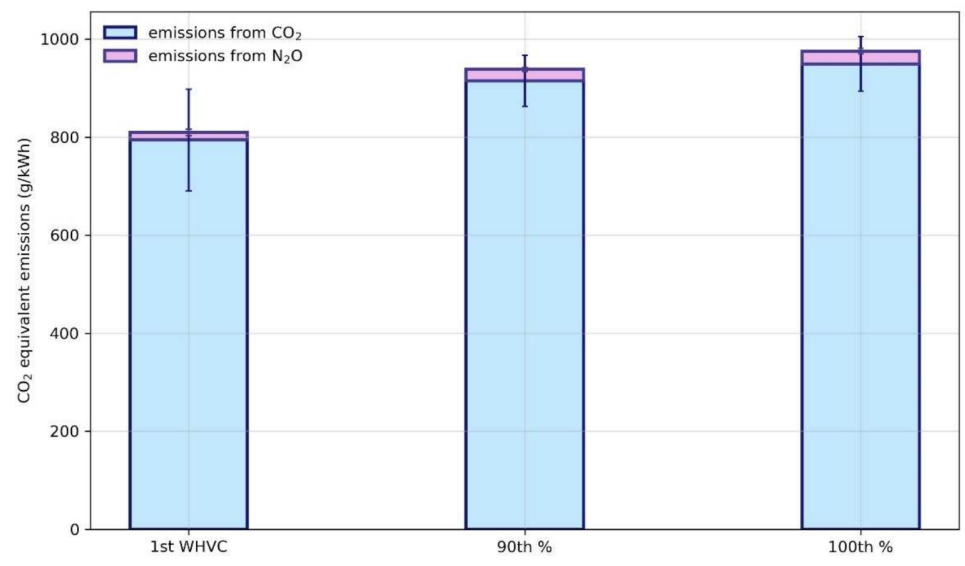

Figure 8. Averaged $\mathrm{CO}_{2}$ equivalent emissions on the complete set of tests. The GWP of $\mathrm{N}_{2} \mathrm{O}$ was assumed to be 298 [27]. The first WHVC refers to tests for which the total work is less or equal to 1 time the reference work. The $90 \mathrm{th} \%$ and $100 \mathrm{th} \%$ refer to the percentiles of the cumulative distribution of work-based MW for tests with length exceeding 3 times the reference work. $\mathrm{CO}_{2}$ emissions reported were measured at the tailpipe. See the "Evaluation Methodology" Section 2.5 for details on the evaluation process. 
To complement the analysis, it should be also noticed that $\mathrm{CO}_{2}$ emissions were lower in the short tests if compared to both 100th and 90th cumulative percentiles of the distribution of windows obtained from long tests. This was mostly due to the fact that short tests comprised a significant number of WHVCs (8 tests), in which, due to the presence of sections of efficient driving on the highway, the $\mathrm{CO}_{2}$ emissions were lower $(728 \mathrm{~g} / \mathrm{kWh})$. In addition, a JRC city drive with long idling periods with low load (762 $\mathrm{g} / \mathrm{kWh}$ ) was also included. The set was completed by only four urban driving cycles for which the vehicle under testing, a long haul N3 truck, was clearly less optimised with average $\mathrm{CO}_{2}$ emissions of $948 \mathrm{~g} / \mathrm{kWh}$. Indeed, in long tests, the worst windows were always related to urban driving patterns, with $\mathrm{CO}_{2}$ emission figures for the 100th percentile $(949 \mathrm{~g} / \mathrm{kWh})$ well in line with those registered in the shorter urban driving cycles.

\subsection{Impact of Active Regeneration Events for Relevant Compound}

Figure 9 shows the emission profiles during the active regeneration of the DPF filter for selected pollutants. Two things should be noticed: (i) during this test, raw gaseous compound measurements were carried out only with a HORIBA MEXA-ONE-QL-NX measuring $\mathrm{NOx}, \mathrm{NH}_{3}$, and $\mathrm{N}_{2} \mathrm{O}$, while all the other tailpipe instruments were not measuring; (ii) the service regeneration procedure was triggered. This is important, since this is the one defined for the EU VI step C production system and has not been specifically adapted for the EU VII demonstrator. In addition, such a procedure is usually only used if the vehicle cannot clean the DPF during normal driving, being therefore a function for hardware protection not to be misunderstood with an active regeneration on the road. The whole test was performed in idling conditions, at an engine speed of $500 \mathrm{rpm}$.

The first important thing was that the regeneration, starting around second 1500, was not complete even after $40 \mathrm{~min}$, considering that approximately $20 \mathrm{~min}$ passed before triggering the regeneration. After the initial increase, the emissions stabilised to about $700 \mathrm{ppm}$ for NOx and $1 \times 10^{10} \mathrm{\#} / \mathrm{s}$ for $\mathrm{SPN}_{23}$. Overall, approximately $148 \mathrm{~g}$ of NOx were emitted during the test, and $2.45 \times 10^{13} \#$ of $\mathrm{SPN}_{23}, \mathrm{~N}_{2} \mathrm{O}$, and $\mathrm{NH}_{3}$ emissions were lower, with rates of $4.1 \mathrm{~g}$ and $0.4 \mathrm{~g}$, respectively. For consistency with the rest of the work, $\mathrm{SPN}_{23}$ are reported in the figure, noticing however that $\mathrm{SPN}_{10}$ was $\sim 10 \%$ higher than the $\mathrm{SPN}_{23}$ during the active regeneration.

Before the regeneration, the emission control system was not conditioned, and the Brenner cycle and the idling test were performed since the last preconditioning procedure. This might be relevant in terms of $\mathrm{NH}_{3}$ and $\mathrm{N}_{2} \mathrm{O}$ emissions, since, as already discussed during the idling test (which was performed just before the regeneration one), a long induction period before NOx breakthrough was recorded. This suggests a progressive consumption of the $\mathrm{NH}_{3}$ stored on the catalyst. Indeed, this might imply that $\mathrm{NH}_{3}$ and $\mathrm{N}_{2} \mathrm{O}$ can be proportionally higher if active regeneration was carried out with a different starting catalyst history, as also shown in the literature [4]. Similarly, for PN, the stored material in the DPF has an influence on the emitted particles [28]. Nevertheless, the total emitted particles of $2.45 \times 10^{13} \#$ of $\mathrm{SPN}_{23}$ were within the range reported for solid particle emissions during "parked" regeneration (1.5-5.1 × 10 ${ }^{13}$ particles) [29]. 

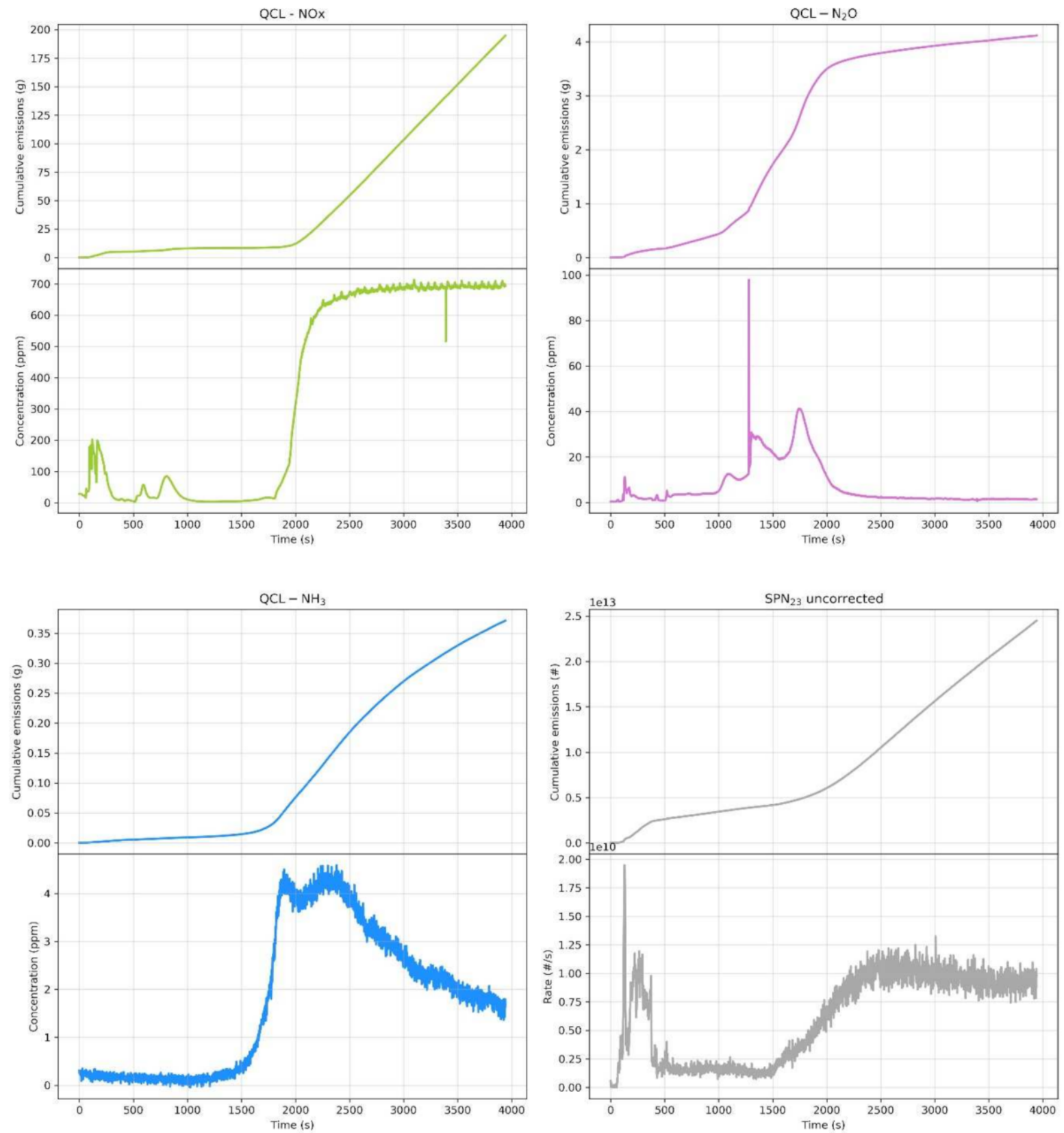

Figure 9. Emissions of selected pollutants ( $\mathrm{NOx}, \mathrm{N}_{2} \mathrm{O}, \mathrm{NH}_{3}, \mathrm{SPN}_{23}$ ) during an active regeneration test at $18{ }^{\circ} \mathrm{C}$, with hot engine and not conditioned emission control system. For each pollutant, the top panel reports cumulative emissions ( $\mathrm{g}$ or \#), while the lower panel instantaneous emissions (ppm or \#/s). All gaseous emissions reported were measured at the tailpipe. See the "Evaluation Methodology" Section 2.5 for details on evaluation procedures.

\subsection{Assessment of Instruments for On-Road Measurement of $\mathrm{N}_{2} \mathrm{O}$ and $\mathrm{NH}_{3}$}

Figure 10 shows the results of the correlations between the $\mathrm{N}_{2} \mathrm{O}$ measured concentrations by two different portable (OBS-ONE-XL and LAS- $\mathrm{N}_{2} \mathrm{O}$ ) and laboratory (AVL SESAM and HORIBA MEXA-ONE-QL-NX) instruments. The whole set of time-aligned $1 \mathrm{~Hz}$ measurement was used for this inter-comparison except for two experiments (a WHVC hot, $23{ }^{\circ} \mathrm{C}, 55 \%$ payload and the RWT cold, $-7{ }^{\circ} \mathrm{C}, 10 \%$ payload) in which the instruments showed a malfunction. 

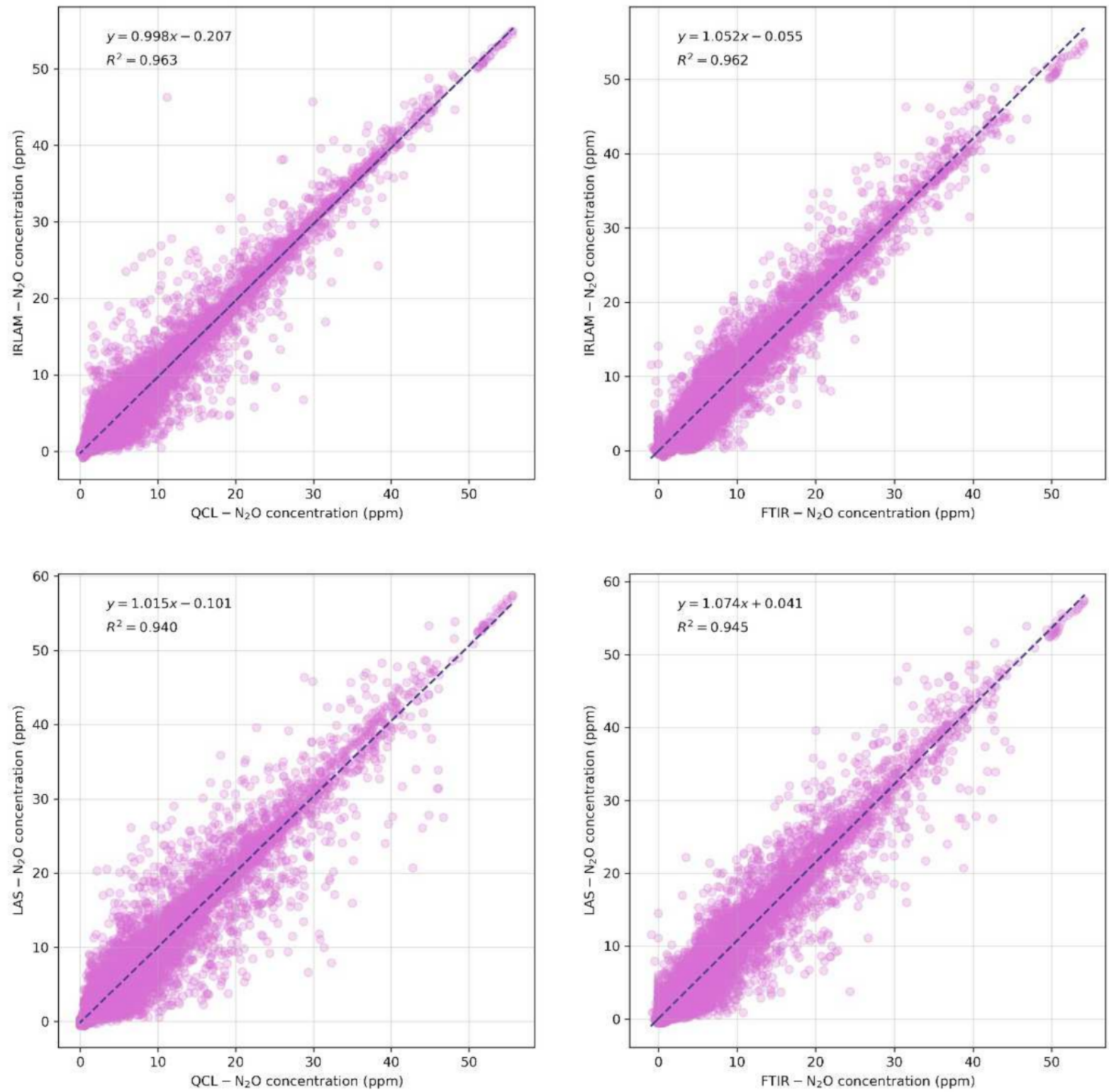

Figure 10. Correlation plots between mobile and stationary instrumentation for $\mathrm{N}_{2} \mathrm{O}$ measurement. Top panels show the correlation of tailpipe concentrations between HORIBA OBS-ONE-XL (IRLAM) and two different laboratory grade instruments (HORIBA MEXA-ONE-QL-NX, namely QCL, left panel and AVL SESAM, namely FTIR, right panel). Bottom panels shows the correlation of tailpipe concentrations between AIP LAS- $\mathrm{N}_{2} \mathrm{O}$ (LAS) and the laboratory grade instruments (HORIBA MEXAONE-QL-NX, namely QCL, left panel and AVL SESAM, namely FTIR, right panel). All concentrations are measured at the tailpipe; see the "Materials and Methods" Section 2 for details on the configuration and the instrumentation.

The upper panels show that the OBS-ONE-XL and both laboratory grade instruments excellently correlated, with an $R^{2}>0.96$ in both cases and a very good linearity, with angular coefficient equal to $1 \pm 0.05$ and intercept $<0.2$. These results were well in line with those obtained for a CNG M1 bus and discussed in [11].

The bottom panels show that also for the AIP LAS- $\mathrm{N}_{2} \mathrm{O}$, measurements excellently correlated with both laboratory grade instruments, with an $R^{2}>0.94$ in both cases and a very good linearity, with angular coefficient equal to $1 \pm 0.07$ and intercept $<0.1$. 
$\mathrm{NH}_{3}$ emissions were generally low for this vehicle, and this was confirmed by all the instruments used in the campaign. Additional details can be found in Figure S9 in Supplementary Materials.

\subsection{Assessment of Onboard Measuring Systems}

Figure 11 reports a comparison between the NOx emissions obtained using the onboard sensors of the vehicle and those determined with laboratory grade instrumentation. In both cases, the flow rate used was the one calculated by subtracting the CVS total flow rate and the measured dilution air. In general, it can be seen that sensors slightly overestimate emissions, with a deviation in the order of $15 \%$ on the median for the short tests and up to $50 \%$ for the 100th cumulative percentile in long tests. The error further increased for the 90th percentile, very likely due to the very low concentrations of NOx measured after the SCR became fully operational, as can be seen in Figure S10 in Supplementary Materials. This promising result showed the potential utilisation of on-board sensors to monitor emissions performance on vehicles on the market; such sensors easily discriminate potentially high emitting behaviours or tampered vehicles, provided that are properly implemented.

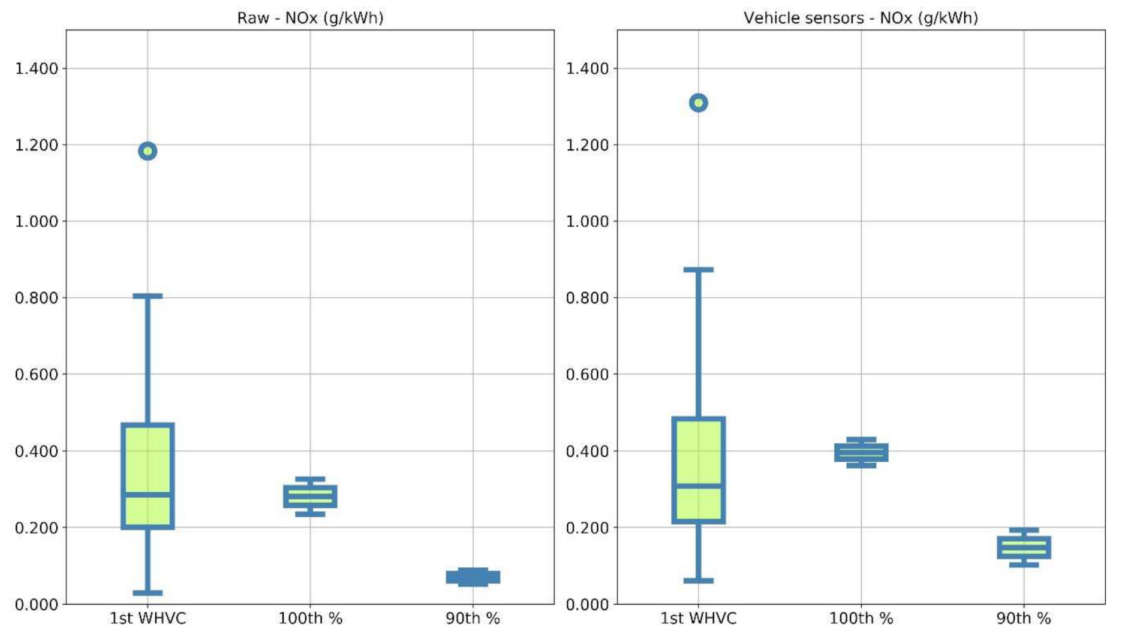

Figure 11. Overall NOx emissions on the complete set of tests computed from laboratory instrumentation ((left) panel) and using on-board sensors ((right) panel). In both cases the exhaust flow rate measured in the laboratory is used. Left panel is the same of the one reported in Figure 1, and it is added only to facilitate the comparison. The first WHVC refers to tests for which the total work is less or equal to 1 time the reference work. The $90 \mathrm{th} \%$ and $100 \mathrm{th} \%$ refer to the percentiles of the cumulative distribution of work-based MW for tests with length exceeding 3 times the reference work. NOx emissions reported were measured at the tailpipe. See the "Evaluation Methodology" Section 2.5 for details on the evaluation process.

\section{Conclusions}

This work summarised the emissions performance of an advanced demonstrator N3 vehicle with a specifically designed emission control system thermally aged to $500 \mathrm{k} \mathrm{km}$ equivalent. The vehicle was tested in the laboratory in a large variety of conditions in terms of ambient temperature (from $-7{ }^{\circ} \mathrm{C}$ to $35^{\circ} \mathrm{C}$ ), payloads $(10-55 \%$ ), and operative conditions ranging from urban delivery cycles to aggressive motorway driving, including idling and DPF regeneration. The demonstrator vehicle and emission control system generally controlled well the emissions, which were substantially lower than those reported for Euro VI vehicles. Still, a large variability in emissions was induced by the broad range of operative conditions, including during cold start. The scattering found due to the impact of the NOx storage capability of the catalyst system, water absorption, and release played a part in the amount of NOx emissions measured during the cold start. Furthermore, effects of temperature and payload also played a role. 
The effect of emission control system conditioning was also explored, showing the importance of a robust control strategy and a properly operating SCR system to effectively reduce NOx emissions, also in challenging operative conditions such as cold start.

Among currently unregulated pollutants investigated, the emissions of $\mathrm{N}_{2} \mathrm{O}$ were the most relevant for this specific vehicle. These seemed to be related to unselective reactions ongoing in particular on the DOC, but this hypothesis requires further investigation. The increase in $\mathrm{CO}_{2}$ equivalent emissions due to $\mathrm{N}_{2} \mathrm{O}$ was approximately $2.5 \%$ under the conditions explored. $\mathrm{N}_{2} \mathrm{O}$ and $\mathrm{NH}_{3}$ were also measured by two new generation portable instruments, which showed excellent correlation with laboratory grade reference instrumentation, supporting the possibility of effectively measuring such species during on-road testing. The increase of particle emissions due to the inclusion of $\mathrm{SPN}_{10}$ were in the order of $20-25 \%$ depending on the testing conditions.

Finally, the performance of on-board sensors for the measurement of NOx was also studied. The assessment showed encouraging results, strengthening the idea that they may be suitable to detect high emitting or tampered vehicles, by monitoring these sensors when properly implemented.

Supplementary Materials: The following are available online at https:/ /www.mdpi.com/article/ 10.3390/catal12020184/s1, Figure S1. ATS scheme. Figure S2. Top: speed profiles and associated slopes of the different cycles performed on the Euro VII demonstrator. Bottom: speed and altitude profiles of the different cycles on the Euro VI step C vehicle. Figure S3. Scheme of the measuring setup used. Figure S4. Detail of $\mathrm{SPN}_{23}$ and $\mathrm{SPN}_{10}$ for the tests performed. Figure S5. Detail of NOx emissions and catalyst temperature in RWT tests. Figure S6. Detail of ATS temperature and NOx emissions in urban delivery tests at different payloads. Figure S7. Detail of ATS temperature and NOx emissions in JRC city test. Figure S8. Detail of $\mathrm{H}_{2} \mathrm{O}$ and NOx emission profiles in the idling test. Figure S9. Comparison of $\mathrm{NH}_{3}$ concentration profiles measured by the different instruments available on selected tests. Laboratory reference is QCL in top panel and FTIR in bottom panel. IRLAM stands for HORIBA OBS-ONE-XL while LAS stands for AIP LAS-NH $\mathrm{N}_{3}$ module. Figure S10. Detailed comparison of NOx concentration profiles measured from on-board sensors and reference laboratory instrumentation. Laboratory reference is QCL in top panel and FTIR in bottom panel. Table S1. Complete list of all tests performed. Conditioning procedure: the vehicle was driven for approximately 30 minutes, until the differential pressure change across the DPF was stable, at high speed $(70 \mathrm{~km} / \mathrm{h})$ with DEF dosing disabled. In this table cold means that the coolant and ATS temperatures are both within $\pm 3{ }^{\circ} \mathrm{C}$ the ambient one. Table S2. HORIBA OBS-ONE-XL (top) AIP LAS analysers (bottom) technical specifications. Table S3. Overall summary of the results obtained (below). Data reported in tables below are to be considered raw, i.e., tailpipe emissions (except for SPN) not corrected for background, drift or similar and simply processed according to the methodology presented in the manuscript. Table S4. Overall summary of boxplot data. Q1, MED, Q3, WHISHI, WHISLO, FLIERS stand for first quartile, median, third quartile, higher whisker, lower whisker and outliers values respectively.

Author Contributions: Conceptualisation, T.S, R.S.-B., R.G., A.P.; Experimental data collection, R.G., A.D.M., O.S., M.S.; Formal analysis, T.S, R.S.-B., A.D.M., B.G.; Writing—original main draft preparation, T.S., A.D.M., R.S.-B.; Writing — additional writing, reviewing and editing, T.S, R.S.-B., R.G., A.P., A.D.M., B.G. (Barouch Giechaskiel), O.S., M.S, F.F., P.M.V., J.D., D.B., T.W., P.R., V.L., Y.O., B.G. (Benedikt Grob). All authors have read and agreed to the published version of the manuscript.

Funding: This research received no external funding.

Data Availability Statement: All relevant data are reported in the Supplementary Materials and can be made available upon request.

Acknowledgments: The authors would like to acknowledge the JRC VELA technical staff and AVL's resident engineer A. Bonamin for their support on the experimental activities. The authors would also like to thank Koen Jonkers for the feedback when reviewing the manuscript.

Conflicts of Interest: The authors declare no conflict of interest. The opinions expressed in this manuscript are those of the authors and should in no way be considered to represent an official opinion of the European Commission and the respective institutes. Mention of trade names or commercial 
products does not constitute endorsement or recommendation by the European Commission, the institutes, and/or the authors.

\section{Abbreviations}

\begin{tabular}{|c|c|}
\hline Acronyms & \\
\hline $4 \mathrm{WD}$ & Four-Wheel Drive \\
\hline ASC & Ammonia Slip Catalyst \\
\hline ATS & After-Treatment System \\
\hline $\mathrm{APC}$ & AVL Particle Counter \\
\hline $\mathrm{CC}$ & Closed Coupled \\
\hline CNG & Compresses Natural Gas \\
\hline $\mathrm{CPC}$ & Condensation Particle Counter \\
\hline CVS & Constant Volume Sampler \\
\hline DEF & Diesel Exhaust Fluid \\
\hline DOC & Diesel Oxidation Catalyst \\
\hline DPF & Diesel Particulate Filter \\
\hline $\mathrm{EC}$ & European Commission \\
\hline EGR & Exhaust Gas Recirculation \\
\hline EU & European Union \\
\hline GWP & Global Warming Potential \\
\hline HD & Heavy-duty \\
\hline HDV & Heavy-duty vehicle \\
\hline ICE & Internal Combustion Engine \\
\hline ICL & Interband Cascade Laser \\
\hline IR & Infrared \\
\hline IPM & Intra-Pulse Modulation \\
\hline IQR & Interquartile Range \\
\hline IRLAM & Infrared Laser Absorption Modulation \\
\hline ISC & In-Service Conformity \\
\hline JRC & Joint Research Centre \\
\hline LAS & Laser Absorption Spectroscopy \\
\hline LoD & Limit of Detection \\
\hline FTIR & Fourier-Transform Infrared spectroscopy \\
\hline MW & Moving Window \\
\hline OBD & On Board Diagnostic \\
\hline OCEs & Off-Cycle Emissions \\
\hline $\mathrm{p}$ & Pressure \\
\hline PEMS & Portable Emission Measurement System \\
\hline PCRF & Particle Correction Reduction Factor \\
\hline PTFE & Polytetrafluoroethylene \\
\hline Q & Quartile \\
\hline QCL & Quantum Cascade Laser \\
\hline RWT & Real World Test \\
\hline SCR & Selective Catalytic Reduction \\
\hline SI & Supporting Information \\
\hline SPN & Solid Particle Number \\
\hline $\mathrm{T}$ & Temperature \\
\hline TA & Type Approval \\
\hline VELA & Vehicles Emissions Laboratories \\
\hline W & Work \\
\hline WHTC & World Harmonised Transient Cycle \\
\hline WHSC & World Harmonised Steady-state Cycle \\
\hline WHVC & World Harmonised Vehicle Cycle \\
\hline Subscripts & \\
\hline $\mathrm{i}$ & pollutant i \\
\hline ref, WHTC & reference in a WHTC cycle \\
\hline
\end{tabular}




\section{References}

1. European Environmental Agency. EEA Report No 09/2020 Air Quality in Europe-2020 Report; Office of the European Union: Luxembourg, 2020; ISBN 978-92-9480-292-7. ISSN 1977-8449. Available online: https:/ /www.eea.europa.eu/publications/soer2020 /at_download/file (accessed on 3 November 2021).

2. Selleri, T.; Melas, A.D.; Joshi, A.; Manara, D.; Perujo, A.; Suarez-Bertoa, R. An Overview of Lean Exhaust deNOx Aftertreatment Technologies and NOx Emission Regulations in the European Union. Catalysts 2021, 11, 404. [CrossRef]

3. Regulation (EC) No 595/2009 of the European Parliament and of the Council of 18 June 2009 on Type-Approval of Motor Vehicles and Engines with Respect to Emissions from Heavy Duty Vehicles (Euro VI) and Amending Regulation (EC) No 715/2007 and Directive 2007/46/EC and Repealing Directives 80/1269/EEC, 2005/55/EC and 2005/78/EC. Available online: http:/ / data.europa.eu/eli/reg/2009/595/2020-09-01 (accessed on 22 October 2021).

4. Suarez-Bertoa, R.; Pechout, M.; Vojtíšek, M.; Astorga, C. Regulated and Non-Regulated Emissions from Euro 6 Diesel, Gasoline and CNG Vehicles under Real-World Driving Conditions. Atmosphere 2020, 11, 204. [CrossRef]

5. Clairotte, M.; Suarez-Bertoa, R.; Zardini, A.A.; Giechaskiel, B.; Pavlovic, J.; Valverde, V.; Ciuffo, B.; Astorga, C. Exhaust emission factors of greenhouse gases (GHGs) from European road vehicles. Environ. Sci. Eur. 2020, 32, 1-20. [CrossRef]

6. Samaras, Z.; Andersson, J.; Aakko-Saksa, P.; Cuelenaere, R.; Mellios, G. Additional Technical Issues for Euro 7 (LDV) 2021. In Proceedings of the AGVES Meeting, Brussels, Belgium, 27 April 2021.

7. Mendoza Villafuerte, P.; Demuynck, J.; Bosteels, D.; Wilkes, T.; Robb, L.; Schönen, M. Demonstration of Extremely Low NOx Emissions with Partly Close-Coupled Emission Control on a Heavy-duty Truck Application, 42nd International Vienna Motor Symposium 2021. 2021. Available online: https://www.aecc.eu/wp-content/uploads/2021/05/210219_Vienna_HD-dieselAECC-FEV-paper-final_v2.pdf (accessed on 22 October 2021).

8. Gioria, R.; Martini, G.; Perujo Mateos Del Parque, A.; Giechaskiel, B.; Carriero, M.; Zappia, A.; Cadario, M.; Forloni, F.; Lähde, T.; Selleri, T.; et al. Assessment of On-Road Emissions of Refuse Collection Vehicles; EUR 30268 EN; Publications Office of the European Union: Luxembourg, 2020; ISBN 978-92-76-19837-6. [CrossRef]

9. Shibuya, K.; Podzorov, A.; Matsuhama, M.; Nishimura, K.; Magari, M. High-sensitivity and low-interference gas analyzer with feature extraction from mid-infrared laser absorption-modulated signal. Meas. Sci. Technol. 2021, 32, 035201-035213. [CrossRef]

10. Onishi, Y.; Hamauchi, S.; Shibuya, K.; McWilliams-Ward, K.; Akita, M.; Tsurumi, K. Development of On- $\mathrm{Board} \mathrm{NH}_{3}$ and $\mathrm{N}_{2} \mathrm{O}$ Analyser Utilizing Mid-Infrared Laser Absorption Spectroscopy. SAE Tech. Pap. 2021. [CrossRef]

11. Suarez-Bertoa, R.; Gioria, R.; Selleri, T.; Lilova, V.; Melas, A.; Onishi, Y.; Franzetti, J.; Forloni, F.; Perujo, A. NH 3 and $\mathrm{N}_{2} \mathrm{O}$ Real World Emissions Measurement from a CNG Heavy Duty Vehicle Using On-Board Measurement Systems. Appl. Sci. 2021, 11, 55. [CrossRef]

12. Lähde, T.; Giechaskiel, B. Particle Number Emissions of Gasoline, Compressed Natural Gas (CNG) and Liquefied Petroleum Gas (LPG) Fueled Vehicles at Different Ambient Temperatures. Atmosphere 2021, 12, 893. [CrossRef]

13. Pandas Documentation. Available online: https://pandas.pydata.org/docs/reference/api/pandas.DataFrame.boxplot.html (accessed on 3 November 2021).

14. Giechaskiel, B.; Melas, A.D.; Lähde, T.; Martini, G. Non-Volatile Particle Number Emission Measurements with Catalytic Strippers: A Review. Vehicles 2020, 2, 19. [CrossRef]

15. Mendoza-Villafuerte, P.; Suarez-Bertoa, R.; Giechaskiel, B.; Riccobono, F.; Bulgheroni, C.; Astorga, C.; Perujo, A. NOx, NH3, $\mathrm{N}_{2} \mathrm{O}$ and PN real driving emissions from a Euro VI heavy-duty vehicle. Impact of regulatory on-road test conditions on emissions. Sci. Total Environ. 2017, 609, 546-555. [CrossRef]

16. Suarez-Bertoa, R.; Clairotte, M.; Arlitt, B.; Nakatani, S.; Hill, L.; Winkler, K.; Kaarsberg, C.; Knauf, T.; Zijlmans, R.; Boertien, H.; et al. Intercomparison of ethanol, formaldehyde and acetaldehyde measurements from a flex-fuel vehicle exhaust during the WLTC. Fuel 2017, 203, 330-340. [CrossRef]

17. Mendoza Villafuerte, P.; Demuynck, J.; Bosteels, D.; Vermeulen, R.; van Gijlswijk, R.; Ligterink, N. Real-World Emissions of Euro VI Heavy-Duty Vehicles. SAE Tech. Pap. 2021. [CrossRef]

18. Giechaskiel, B.; Gioria, R.; Carriero, M.; Lähde, T.; Forloni, F.; Perujo, A.; Martini, G.; Bissi, L.M.; Terenghi, R. Emission Factors of a Euro VI Heavy-duty Diesel Refuse Collection Vehicle. Sustainability 2019, 11, 1067. [CrossRef]

19. Grigoratos, T.; Fontaras, G.; Giechaskiel, B.; Zacharof, N. Real world emissions performance of heavy-duty Euro VI diesel vehicles. Atmos. Environ. 2019, 201, 348-359. [CrossRef]

20. Frey, H.C.; Rouphail, N.M.; Zhai, H. Link-Based Emission Factors for Heavy-Duty Diesel Trucks Based on Real-World Data. Transp. Res. Rec. 2008, 2058, 23-32. [CrossRef]

21. Wang, C.; Wu, Y.; Jiang, J.; Zhang, S.; Li, Z.; Zheng, X.; Hao, J. Impacts of load mass on real-world PM1 mass and number emissions from a heavy-duty diesel bus. Int. J. Environ. Sci. Technol. 2015, 12, 1261-1268. [CrossRef]

22. Colombo, M.; Nova, I.; Tronconi, E.; Schmeißer, V.; Bandl-Konrad, B.; Zimmermann, L. NO/ $\mathrm{NO}_{2} / \mathrm{N}_{2} \mathrm{O}-\mathrm{NH} 3 \mathrm{SCR}$ reactions over a commercial Fe-zeolite catalyst for diesel exhaust aftertreatment: Intrinsic kinetics and monolith converter modelling. Appl. Catal. B Environ. 2012, 111-112, 106-118. [CrossRef]

23. Nova, I.; Colombo, M.; Tronconi, E.; Schmeisser, V.; Bandl-Konrad, B.; Zimmermann, L. Experimental and Modelling Study of a Dual-Layer $\mathrm{NH}_{3}$ Slip Monolith Catalyst for Automotive SCR Aftertreatment Systems. Top. Catal. 2013, 56, 227-231. [CrossRef]

24. Kamasamudram, K.; Henry, C.; Currier, N.; Yezerets, A. $\mathrm{N}_{2} \mathrm{O}$ Formation and Mitigation in Diesel Aftertreatment Systems. SAE Int. J. Engines 2012, 5, 688-698. [CrossRef] 
25. Schmeisser, V.; Weibel, M.; Sebastian Hernando, L.; Nova, I.; Tronconi, E.; Ruggeri, M.P. Cold Start Effect Phenomena over Zeolite SCR Catalysts for Exhaust Gas Aftertreatment. SAE Int. J. Commer. Veh. 2013, 6, 190-199. [CrossRef]

26. Ravishankara, A.R.; Daniel, J.S.; Portmann, R.W. Nitrous Oxide $\left(\mathrm{N}_{2} \mathrm{O}\right)$ : The Dominant Ozone-Depleting Substance Emitted in the 21st Century. Science 2009, 326, 123-125. [CrossRef]

27. IPCC. Climate Change 2014: Synthesis Report; Contribution of Working Groups I, II and III to the Fifth Assessment Report of the Intergovernmental Panel on Climate Change; Core Writing Team, Pachauri, R.K., Meyer, L.A., Eds.; Cambridge University: Cambridge, UK, 2014.

28. Giechaskiel, B. Particle Number Emissions of a Diesel Vehicle during and between Regeneration Events. Catalysts 2020, 10, 587. [CrossRef]

29. Giechaskiel, B. Solid Particle Number Emission Factors of Euro VI Heavy-Duty Vehicles on the Road and in the Laboratory. Int. J. Environ. Res. Public Health 2018, 15, 304. [CrossRef] 